\title{
Kommunale Bauplanung in Rom
}

\author{
Urkunden, Inschriften und Statuten vom 12. bis 14. Jahrhundert
}

\author{
Winfried Stelzer \\ zum 60. Geburtstag
}

\begin{abstract}
Wer sich aber erdreistet, gegen diese Verordnung zu handeln, zieht sich den Unwillen und den dauerhaften Zorn des heiligen Senats sowie die Ungnade des hochwürdigen römischen Volkes zu und verfällt zudem einer Strafe von einem Pfund Gold, wovon die Hälfte für die Wiederherstellung der Stadtmauern aufzuwenden ist. ${ }^{1}$
\end{abstract}

Mit dieser Poenformel stellte 1235 der römische Senator Angelo Malabranca die gewinnsüchtigen Bewohner der Leostadt und der angrenzenden Wohngebiete unter Bußandrohung. Die habgierigen Vorstädter hatten sich angewöhnt, die Pilger nach Beginn der Nachtruhe aus den Hospizen zu zerren und gewaltsam in ihre eigenen Häuser umzuquartieren. Die Anstrengungen der Stadt im Bereich der öffentlichen Bauplanung zeigen sich beim Verwendungszweck der Buße für die Wiederherstellung der Stadtmauern. Die Reparatur der städtischen Befestigungsanlagen muß dem Senat so wichtig gewesen sein, daß er sie als festen Bestandteil in das Urkundenformular integrierte, um deren Vorrang in der kommunalen Finanzpolitik publikumswirksam zu proklamieren.

Zur Verwirklichung einer autonomen Regierung unter kollektiver Mitwirkung versuchten italienische Kommunen nach ihrer Konstituierung, die zentralen Aufgaben der Verwaltung und Gerichtsbarkeit an sich zu ziehen und zu bewältigen. Ein solches Vorgehen läßt sich auch in der Stadt Rom erkennen, als die politische Ordnung infolge von macht- und territorialpolitischen Streitigkeiten mit dem Papst im Juli 1143 umgestürzt und spätestens im Spätsommer 1144 eine neue Regierung gebildet worden war. Allerdings unterscheiden sich die Voraussetzungen und Entwicklungsphasen teilweise grundlegend von der norditalienischen Kommunebewegung: ${ }^{2} \mathrm{Zu}$ beseitigen war die Stadtherrschaft des

1 Franco Bartoloni, Codice diplomatico del Senato Romano dal MCXLIV al MCCCLVII, Bd.1 (bis 1262, mehr nicht erschienen), Roma 1948 (Fonti per la storia d'Italia 87), Nr.86, S.145: „Si quis autem hoc attemptare presumpserit, indignationem et iram perpetuam sacri senatus et reverentissimi populi Romani offensam incurret et insuper incidat in penam unius libre auri, cuius medietas refectioni murorum Urbis applicetur".

2 Zum Begriff Kommune vgl. u.a. die immer noch grundlegenden Studien von Hagen Keller, Die Entstehung der italienischen Stadtkommunen als Problem der Sozialge- 
Universalherrschaft beanspruchenden Papstes, nicht eines übertragene Rechte ausübenden Bischofs; die Einsetzung kommunaler Institutionen erfolgte Jahrzehnte später als in Norditalien, die Bezeichnungen Senat und Senatoren evozierten die einzigartige antike Vergangenheit, während der Titel consul anfangs weiterhin einer traditionellen Führungsschicht vorbehalten blieb; zudem war die neu etablierte Ordnung einer bürgerlichen Stadtgemeinde, die mangels ausreichender Quellen nur schwer zu fassen ist, bald größeren Veränderungen unterworfen, da Päpste, Kaiser und innerstädtische Adelscliquen immer wieder massiv eingriffen, um ihre politischen Ziele durchzusetzen. ${ }^{3}$

Für Rom ist der idealtypisch für Norditalien definierte Kommune-Begriff deshalb nur im Bewußtsein dieser grundlegenden Modifikationen anzuwenden, auch wenn sich darüber hinaus zahlreiche Gemeinsamkeiten zeigen. Auch der zumindest anfangs von breiteren Bevölkerungsschichten getragene römische Senat erstrebte den Ausbau kommunaler Institutionen, die Ausübung der Gerichtsgewalt, die Ausdehnung der territorialen Vorherrschaft sowie vor allem die Verfügungsgewalt über die öffentlichen Gebäude der Stadt und deren unmittel-

schichte, in: Frühmittelalterliche Studien 10(1976), S.169-211; ders., Wahlformen und Gemeinschaftsverständnis in den italienischen Stadtkommunen (12./14.Jahrhundert), in: R.Schneider/H.Zimmermann (Hg.), Wahlen und Wählen im Mittelalter, Sigmaringen 1990 (Vorträge und Forschungen 37), S.345-374; Gerhard Dilcher, Bürgerrecht und Stadtverfassung im europäischen Mittelalter, Köln/Weimar/Wien 1996; zusammenfassend Knut Schulz, „Denn sie lieben die Freiheit so sehr...“. Kommunale Aufstände und Entstehung des europäischen Bürgertums im Mittelalter, Darmstadt 1992, S.5ff. und S.133-161.

3 Zu den einzelnen Phasen vgl. Franco Bartoloni, Per la storia del Senato Romano nei secoliXII e XIII, in: Bullettino dell'Istituto Storico Italiano per il Medio Evo e Archivio Muratoriano 60(1946), S.1-108; Antonio Rota, La costituzione originaria del comune di Roma, in: Bullettino dell'Istituto Storico Italiano per il Medio Evo e Archivio Muratoriano 64(1953), S.19-131; Laura Moscati, Alle origini del comune romano. Economia, società, istituzioni, Roma 1980 (Quaderni di Clio 1); Robert L.Benson, Political Renovatio: Two Models from Roman Antiquity, in: Renaissance and Renewal in the Twelfth Century, hg. von Robert L. Benson/Giles Constable, Cambridge/Mass. 1982, S.339-386; Schulz, „Denn sie lieben die Freiheit so sehr..." (wie Anm.2), S.133-161; Ingrid Baumgärtner, Rombeherrschung und Romerneuerung. Die römische Kommune im 12.Jahrhundert, in: Quellen und Forschungen aus italienischen Archiven und Bibliotheken 69 (1989), S.27-79; Dies., Rom. Studien zu Stadt und Kommune vom Beginn des 12. bis zur Mitte des 13. Jahrhunderts, mit Regesten zu Urkunden des Fonds S.Maria in Via Lata. Masch.schr. Habilitationsschrift an der Philosophischen Fakultät II der Universität Augsburg 1992; Matthias Thumser, Rom und der römische Adel in der späten Stauferzeit (Bibliothek des Deutschen Historischen Instituts in Rom 81), Tübingen 1995. Eigenwillige Thesen zur Verwendung des Begriffs „Kommune“ für die römische Bürgerschaft, die angeblich frühestens 1220 und spätestens mit der erstmaligen Benennung des Gemeinwesens als comunis in einer Senatsurkunde von 1257 so zu bezeichnen ist, vertritt Jürgen Strothmann, Kaiser und Senat. Der Herrschaftsanspruch der Stadt Rom zur Zeit der Staufer (Archiv für Kulturgeschichte, Beiheft 47), Köln/Weimar/Wien 1998 , bes. S. $217 \mathrm{ff}$. 
barer Umgebung. Vordringlichstes Problem war die strategische Sicherung der Stadt, um die Herrschaft nach innen und außen zu demonstrieren. Deshalb erfolgten die Renovierung und der Bau der Stadtmauern, die Ausbesserung und Überwachung der Zufahrtswege und Brücken sowie die Inbesitznahme öffentlicher Gebäude und Monumente. Die spätere Sorge galt der Instandhaltung öffentlicher Anlagen und Wege, der Überwachung bürgerlicher und kirchlicher Bauvorhaben sowie der Realisierung eigener Bauprojekte.

Die folgenden Ausführungen richten sich darauf, den Anteil der Kommune und zeitweisen Oligarchie unter einer päpstlichen Signorie am Erscheinungsbild der hochmittelalterlichen Stadt zu bemessen, sozusagen den römischen Senat in seiner sich wandelnden Zusammensetzung als eigenständige gestalterische Kraft zu begreifen. Zu fragen ist, ob und wie sich mit der Entfaltung des Senats und den damit verbundenen neuen Formen der bürgerlichen Selbstverwaltung das Bewußtsein von der Gestaltung der eigenen Stadt veränderte, von welchem Zeitpunkt an sich ein solcher Zusammenhang konstatieren läßt und welche Quellen uns darüber unterrichten. Für die kommunalen Anfänge sind die Antworten der kunstgeschichtlichen Forschung auf diese Fragen eher dürftig, zumal bauliche Beispiele außerhalb des Bereichs traditioneller christlicher Ikonographie relativ selten sind. Die Porta Romana in Mailand, erbaut 1171 nach der Rückkehr der Bewohner in ihre von Friedrich Barbarossa 1162 vollkommen zerstörte Stadt, dürfte eines der frühesten Monumente sein, das eine Verbindung zwischen dem Aufbau der Verteidigungsmauern und der Realisierung kommunaler Machtdarstellung in der künstlerischen Ausgestaltung einzelner Elemente erkennen läßt. ${ }^{4}$ Doch nicht nur öffentliche Bauwerke und daran angebrachte Inschriften, die das Objekt öffentlich kommentierten, informieren uns über die Bauaktivitäten städtischer Institutionen, sondern auch Urkunden, Schiedssprüche, Einzelgesetze und Statuten, Zeugnisse also, die in interdisziplinärer Zusammenarbeit zwischen Kunst- und Rechtsgeschichte näher zu untersuchen sind. Denn gerade dieses spröde Rechtsschrifttum, dessen systematische Aufarbeitung in modernen Editionen häufig noch aussteht, liefert zuweilen entscheidende Hinweise auf Normen und Praxis der Stadtgestaltung sowie deren Funktion im städtischen Zusammenhang.

Am Beispiel der Stadt Rom und des 1143/44 eingesetzten römischen Senats soll im folgenden der Zusammenhang zwischen der Erfassung des städtischen Raumes, den einzelnen Maßnahmen der Bauplanung, der Form ihrer öffentlichen Bekanntmachung und der institutionellen Entwicklung der Stadt veranschaulicht werden. Welche Maßnahmen erfolgten zur Wahrung und Gestaltung

4 Vgl. Andrea von Hülsen-Esch, Romanische Skulptur in Oberitalien als Reflex der kommunalen Entwicklung im 12.Jahrhundert. Untersuchungen zu Mailand und Verona, Berlin 1994. Zum Verhältnis zwischen politischem Ordnungsdenken und städtischen Bauprogrammen allgemein vgl. Wolfgang Braunfels, Abendländische Stadtbaukunst. Herrschaftsform und Baugestalt, 3.Auft. Köln 1979. 
des städtischen Baubestands? Wann setzten entsprechende Anordnungen ein, und welchen Zweck verfolgten sie? Welche politischen Gruppierungen zeichneten dafür verantwortlich? Grundlage der folgenden Ausführungen sind, außer einzelnen Inschriften senatorischer Auftraggeber, verschiedene Arten von Rechtsdokumenten, vor allem erstens die zwischen 1144 und 1262 vom Senat ausgestellten Briefe und Urkunden, deren Überlieferung erst fünf Jahre nach der Kommunegründung einsetzt, ${ }^{5}$ zweitens die über Schiedssprüche bekannte Rechtsprechung der Senatoren in Zivilangelegenheiten sowie drittens die erste erhaltene römische Statutenkompilation von $1363,{ }^{6}$ die das Ordnungsbedürfnis eines nach 1358 unter der Signorie des avignonesischen Papstes etablierten und von aufsteigenden Schichten getragenen popolaren Stadtregiments widerspiegelt, von dem Barone und Aristokraten ausgeschlossen waren.

Diese aus sehr unterschiedlichen politischen Situationen und Verfassungsformen hervorgegangenen Rechtsquellen verweisen in den zwei Jahrhunderten zwischen 1144 und 1363 auf vier Bereiche einer Baugesetzgebung und Bauplanung, nämlich erstens die umgehend erforderliche Sicherung der städtischen Infrastruktur mit Stadtbefestigung, Zufahrtswegen und Wasserversorgung, zweitens den Schutz antiker Monumente und christlicher Kirchen gleichsam als Gradmesser für Stadtqualität, drittens die kontinuierliche Bauaufsicht und Überwachung des städtischen Baubestands sowie viertens eine zunächst langsam einsetzende, eigenständige kommunale Bautätigkeit.

\section{Sicherung der städtischen Infrastruktur: Zufahrtswege, Stadtbefestigung und Wasserversorgung}

Sofort nach der Gründung der Kommune setzten die Bemühungen um eine Verbesserung der städtischen Infrastruktur ein. Restaurationsarbeiten an der Stadtmauer und an wichtigen Zufahrtswegen wurden begonnen und blieben in den nächsten beiden Jahrhunderten eine ständige Sorge des öffentlichen Bauwesens. Bereits in einem der ersten schriftlichen Dokumente, einem Brief des Senats an König Konrad III. aus dem Jahre 1149, wird im Zusammenhang mit der dringenden Bitte um einen Romzug des Königs erwähnt, der Senat sei damit beschäftigt, unter großen Anstrengungen die Milvische Brücke zu restaurieren. ${ }^{7}$

5 Ediert von Bartoloni, Codice diplomatico (wie Anm.1).

6 Ediert von Camillo Re (Hg.), Statuti della città di Roma del secolo XIV, Roma 1883.

7 Bartoloni, Codice diplomatico (wie Anm.1), Nr.5, S.5: „sciatis preterea quia pontem Mulvium extra Urbem parum longe, per tempora multa pro imperatorum contrario destructum, nos, ut exercitus vester per eum transire queat, ne [filii] Petri Leonis per castellum Sancti Angeli vobis nocere possint, ut statuerant cum papa et Siculo, magno conamine restauramus et in parvi temporis spacio muro fortissimo et silicibus iuvante Deo complebitur." Zum hochmittelalterlichen Straßenbau der Kommunen Mittel- und Süd- 
Die Brücke, die zur Zeit Kaiser HeinrichsV. zerstört und seitdem nicht wieder aufgebaut worden war, besaß für die neu gegründete Kommune wegen der lokalpolitischen Streitigkeiten mit Papst Eugen III. und seinem mächtigen Verbündeten König Roger von Sizilien eine wichtige strategische Funktion, die auf dem beiliegenden schematischen Stadtplan (Karte) deutlich zu erkennen ist: Der Wiederaufbau sollte Ankömmlingen aus dem Norden den direkten Zugang zur Stadt über die Via Flaminia ermöglichen, da der traditionelle Zufahrtsweg aus dem Norden über die Via Triumphalis und den Monte Mario von der päpstlichen Partei, die sich im Castel S. Angelo verschanzt hatte, bewacht wurde. Die Restaurierung einer solchen Brücke war also ein zentrales, in der aktuellen Lage sogar lebenswichtiges Vorhaben der kommunalen Anfangsphase.

Ein weiteres akutes Problem stellten die Verteidigungsanlagen, Sinnbild städtischer Macht und Freiheit, dar. Römische Stadtbefestigung war im Hochmittelalter immer noch die über 20km lange, 271 errichtete Aurelianische Mauer, die im Laufe der Jahrhunderte zu einem überdimensionalen Ring geworden war und keineswegs mehr die Grenze eines kompakten Siedlungsgebietes darstellte. Die von Papst LeoIV. veranlaßte Befestigung des vatikanischen Borgo bildete einen Zusatz aus der Mitte des 9. Jahrhunderts. Bewohnt war nur ein Bruchteil der antiken Stadtfläche: Kaum mehr als 35000 Einwohner dürften gemäß unsicheren Schätzungen im 12. und 13.Jahrhundert die Ruinen der ehemaligen Millionenstadt belebt haben. Die im 10. und 11. Jahrhundert vorherrschende Streuung der Bebauung wich in dieser Zeit einer zunehmenden Zentrierung der Häuser auf die Tiberschleife, so daß das Gebiet innerhalb der Stadtmauern in den kompakt besiedelten abitato und den ländlich geprägten disabitato mit verschiedenen Siedlungsinseln strukturiert war (Karte). ${ }^{8}$

Das ausgeprägte Verantwortungsbewußtsein der Kommune für die Stadtmauern belegen einige lateinische Inschriften, die mit den profanen Bauwerken überlebten. Eine marmorne Gedächtnistafel aus dem Jahre 1157 (Abb. 1), eingelassen an der Torre della Marana bei der Porta Metronia ( $\mathrm{H}$ auf der Karte) im Süden der Stadt, verweist auf ausgiebige Restaurationsarbeiten an der Stadtbefestigung, die seit der Zerstörung durch die Normannen unter Robert Guiscard (1084) nur noch ungenügend Schutz bot. Auftraggeber war der Senat, bezeichnet

italiens vgl. Thomas Szabó, Comuni e politica stradale in Toscana e in Italia nel Medioevo (Biblioteca di storia urbana medievale 6), Bologna 1992, S.83-86 und 115-118; zur Bedeutung von Brücken vgl. Erich Maschke, Die Brücke im Mittelalter, in: Historische Zeitschrift 224(1977), S.254-292.

8 Ein anschauliches Bild vom Aussehen der Stadt vermitteln Richard Krautheimer, Rom. Schicksal einer Stadt 312-1308. Übers. von T. Kienlechner und U.Hoffmann, München 1987, S.255-356; Étienne Hubert, Espace urbain et habitat à Rome du X $\mathrm{X}^{\mathrm{C}}$ siècle à la fin du XIIIe siècle (Collection de l'École Française de Rome 135 und Nuovi studi storici 7), Rom 1990; aus dieser Studie stammt auch die Vorlage für die beiliegende, nach den konkreten Bedürfnissen des Aufsatzes modifizierte Karte. 


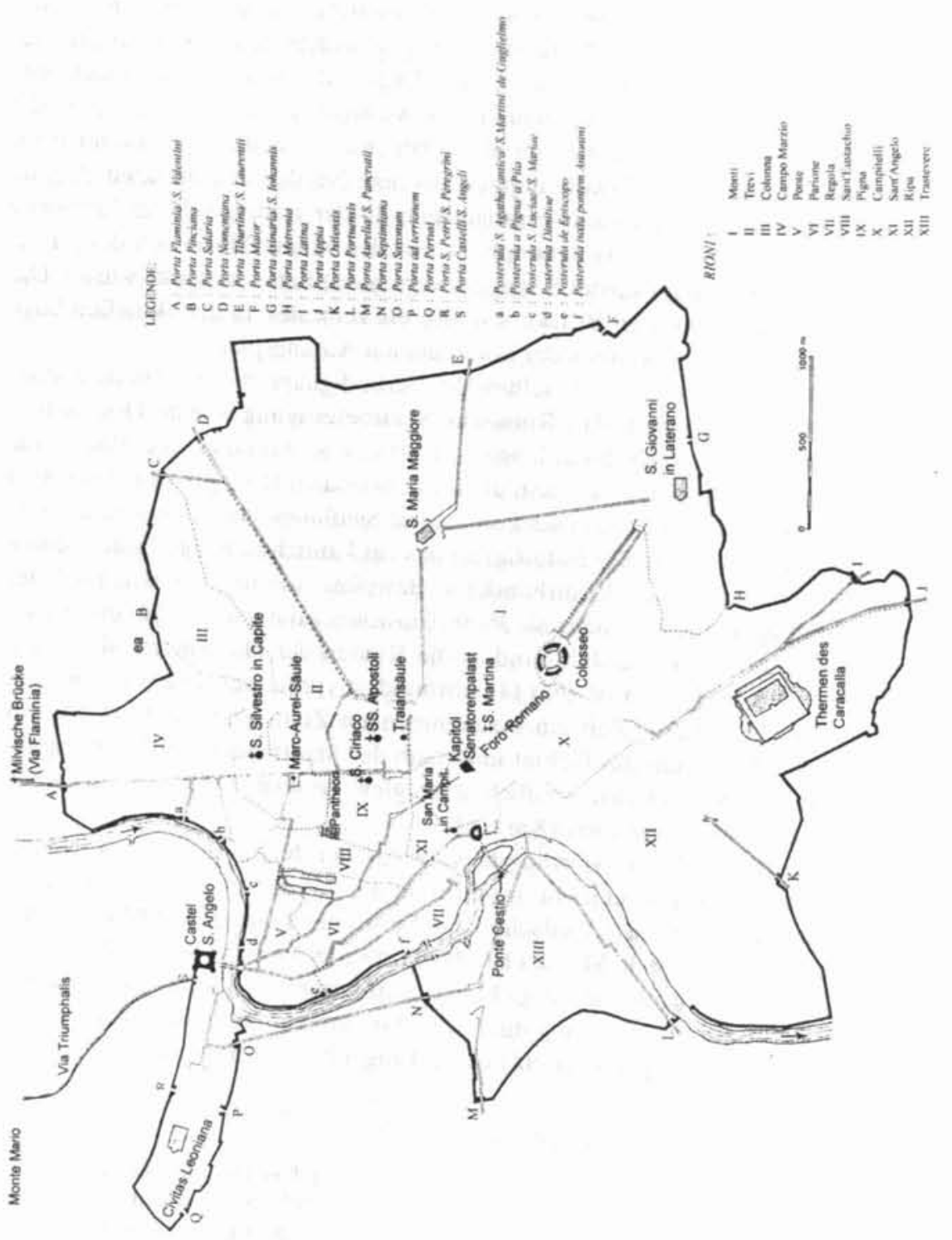


mit der alten Formel SPQR, der damit anschaulich bekundete, vom Papst die Aufgabe der Erhaltung der Stadtmauern übernommen zu haben; auf der Inschrift waren zudem die Namen aller beteiligten Senatoren eingraviert. ${ }^{9}$ Die Ausführung der Inschrift auf Marmor in der gebräuchlichen Capitalis, also mit Majuskeln, und ihre Anbringung an der Innenseite eines Stadttores unterstützten den beabsichtigten Wirkungseffekt, die Zuständigkeit des Senats öffentlich bekanntzugeben. Mit der kommunalen Kraft des 12. Jahrhunderts setzte sich also ein neue Macht durch, die alte Ziele und alte Publikationsformen aufgriff und für eigene Zwecke umfunktionierte.

Ähnliche Absichten verfolgte sicherlich auch eine Inschrift am Ponte Cestio, der wichtigen Verbindungsbrücke zwischen Stadtkern und Trastevere bei der Tiberinsel. Die vom Schriftbild her gleichmäßigere Inschrift besagt, daß Benedictus Carushomo, höchster und einziger Senator des Jahres 1192, die fast einstürzende Brücke erneuern ließ. ${ }^{10}$ Der vom Volk ohne die Zustimmung des frisch gewählten Papstes Coelestin III. und der ihm verbundenen Führungselite eingesetzte Benedictus, der anscheinend der städtischen Mittelschicht entstammte, war durch einen Umschwung als erster von mehreren im folgenden Jahrzehnt allein regierenden Senatoren an die Macht gekommen, um den bis zum Jahr 1191 kontinuierlich als Kollegium mit einer stark variierenden Mitgliederzahl fungierenden Senat abzulösen. Sein effektives Regiment versuchte offensichtlich auch, die baulichen Einrichtungen der Bürgerschaft zu sichern und zu renovieren. Und propagandistischer als an diesem stark frequentierten Platz hätte der neue durchsetzungskräftige Senator, der auch das erste, nur in einem Brief Papsts In-

9 Vincenzo Forcella (Hg.), Iscrizioni delle chiese e d'altri edifici di Roma dal secoloXI fino ai giorni nostri, 14Bde., Roma 1869-1884, Bd.13, S.25, Nr.1: „Regio S. Angeli + anno 1157 incarnationis domini nostri Iesu Christi, SPQR haec moenia vetustate dilapsa restauravit senatores Sasso, Iohannes de Alberico, Roieri Buccacane, Pinzo, Filippo, Iohannes de Parenzo, Petrus Deustesalvi, Cencio de Ansoino, Rainaldo Romano, Nicola Mannetto“. Vgl. Giuseppe Tomassetti, Della campagna romana nel medio evo, parte seconda: Via Latina, in: Archivio della R. Società romana di storia patria 8(1885), S. 10; Bartoloni, Per la storia del Senato Romano (wie Anm.3), S.79 mit Senatorenliste; Ferdinand Gregorovius, Geschichte der Stadt Rom im Mittelalter vom 5. bis zum 16. Jahrhundert, Bd. 4 und 5, Stuttgart 1890 und 1892, Buch VIII, Kap.7.4, gekürzte Fassung, hg. von W.Kampf, 4Bde., Darmstadt 1978, hier Bd.II,1 S.285.

10 Forcella, Iscrizioni delle chiese (wie Anm.9), Bd.13, S.53: „Benedictus alme urbis summus senator restauravit hunc pontem pere dirutum"; Senatorenliste bei Bartoloni, Per la storia del Senato Romano (wie Anm.3), S.86; zur Person und zum Regierungsstil vgl. Laura Moscati, Benedetto "Carushomo" summus senator a Roma, in: Miscellanea in onore di Ruggero Moscati, Napoli 1985, S.73-87; Thumser, Rom und der römische Adel (wie Anm.3) S.239-241 und 354 mit einer chronologischen Liste der Senatoren von 1191 an; Strothmann, Kaiser und Senat (wie Anm.3) S.291-301. Zur städtischen Identitätsstiftung durch diese Bauinschriften vgl. Steffen Diefenbach, Beobachtungen zum antiken Rom im hohen Mittelalter: Stadtische Topographie als Herschafts- und Erinnerungsraum, in: Römische Quatalschrift für christliche Alterskunde und Kirchengeschichte 97 (2002) S. 40-88, hier S. 68-71. 


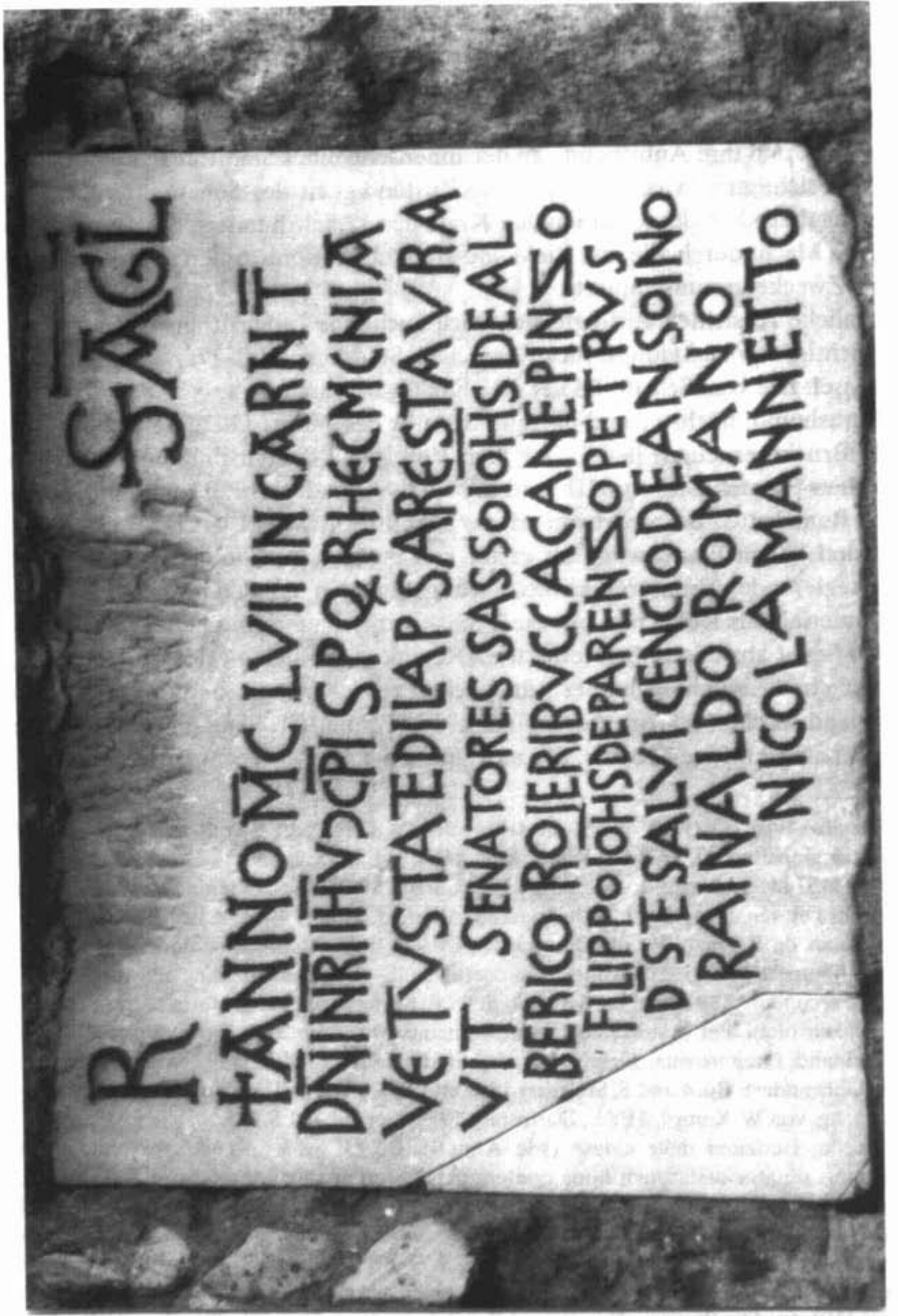

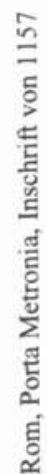

से 
nocenz III. erwähnte Statut der Stadt erlie $\beta,{ }^{11}$ seine praktische Handlungskompetenz nicht unterstreichen können.

Die eigenmächtige Wahrnehmung des Befestigungsrechts mit der Herrschaft über Stadtmauern und Brücken war und blieb ein Symbol kommunaler Autonomie. In dem zwischen dem römischen Senat und Papst Clemens III. 1188 abgeschlossenen Vertrag zur Restitution des Papstes in seine traditionellen Hoheitsrechte über Rom forderte der Senat vom Papst, trotz der vereinbarten Rückgabe aller Regalien, noch einzelne Hoheitsrechte, darunter nicht nur ein Drittel der städtischen Münze, sondern auch die Verfügungsgewalt über den Ponte Lucano, eine strategisch wichtige Brücke kurz vor Tivoli, ${ }^{12}$ und die jährliche Entrichtung von 100 Pfund Silbermünzen für die Instandhaltung der Stadtmauern. ${ }^{13}$ Trotz des groß angelegten Regalienverzichtes hielten also die Senatoren an einem Teil ihrer Verantwortung fest. Die nach einem in der Nähe liegenden antiken Grab benannte Brücke über die Aniene, deren Besitz die Kontrolle über einen zentralen Zugang zum Territorium der römischen Rivalin gewährleistete, besaß ihre spezielle Bedeutung aufgrund der traditionellen Feindschaft zwischen Römern und Tivolesen, die sich aufgrund der Lage Tivolis am oberen Abhang der Monti Tiburtini mit Ausblick auf die römische Ebene immer wieder verschärfte und in die sich der Papst gemäß einer vertraglichen Festlegung nicht einmischen durfte. Die tiefgreifende Symbolkraft der Stadtbefestigung hingegen zeigt sich daran, daß entsprechende päpstliche Abgaben an den Senat gleichermaßen für die Stadt Tusculum vereinbart wurden, die den Römern im nächsten halben Jahr zur vollkommenen Zerstörung freigegeben werden sollte. ${ }^{14}$

Die Forderungen waren vermutlich eine Reaktion auf den Frieden von Konstanz (1183), in dem den freien Städten Italiens unter anderem auch das Befesti-

11 Bartoloni, Codice diplomatico (wie Anm.1), Nr.47; vgl. dazu Ingrid Baumgärtner, Die normativen Grundlagen des Rechtslebens in der Stadt Rom und die Entwicklung der Gesetzgebung, in: Renaissance du pouvoir législatif et genèse de l'État, hg. v. André Gouron und Albert Rigaudière, Montpellier 1988, S.13-27, hier S.21f.

12 Bartoloni, Codice diplomatico (wie Anm.1), Nr.42, S.72: „reddimus omnia regalia tam infra quam extra Urbem que tenemus, preter pontem Lucanum"; zur Brücke vgl. Giuseppe Tomassetti, La Campagna Romana antica, medioevale e moderna, ND bearb. v. L. Chiumenti u. F. Bilancia, Bd.1-7, Città di Castello 1975-1980 (Arte e archeologia 1218), hier Bd.6: Via Nomentana e Salaria, Portuense, Tiburtina, 1979, S.604; G.M.De Rossi, Torri medievali della Campagna Romana, Rom 1981, S.273f. Zum Vertrag vgl. Jürgen Petersohn, Der Vertrag des römischen Senats mit Papst ClemensIII. (1188) und das Pactum Friedrich Barbarossas mit den Römern (1167), in: Mitteilungen des Instituts für Österreichische Geschichtsforschung 82(1974), S.289-337; Paolo Brezzi, Roma e l'impero medioevale (774-1252), Bologna 1947 (Storia di Roma 10), S.371-374.

13 Bartoloni, Codice diplomatico (wie Anm.1), Nr.42, S.72: "dabitis singulis annis pro restauratione murorum huius excellentissime Urbis .c libras bonorum proveniensium"; vgl. Re, Statuti della città di Roma (wie Anm. 6), S.XCIX.

14 Bartoloni, Codice diplomatico (wie Anm. 1), Nr.42, S.72-73. 
gungsrecht zugestanden worden war. ${ }^{15}$ Auch wenn Rom selbstverständlich nicht zum Kreis der vom Kaiser begünstigten Städte gehörte, dürfte sich die Gewährung des Vorrechts trotzdem allgemein ausgewirkt haben. Die Mauer war gleichsam letztes Sinnbild kommunaler Macht und Freiheit, an dem die römischen Senatoren selbst noch festhielten, als sie die anderen Regalien innerhalb und außerhalb der Stadt weitgehend an den Papst restituierten.

Im Gegensatz zu anderen Städten stellte sich in Rom aber das Problem, den überdimensionalen, vielfach baufällig gewordenen Mauerring einer antiken Millionenstadt zu unterhalten. Wie konnten die erforderlichen Mittel dafür aufgebracht werden? Antwort geben uns die eingangs zitierten Poenformeln der Senatsurkunden, die im Gegensatz zu den häufig spirituellen Strafen der Papsturkunden sehr konkret formuliert waren. Hier wurden keine allgemeinen Verfluchungen oder Drohungen mit Höllen- und Gletscherstrafen angekündigt, sondern es drohte der unmittelbare Zorn des Senats, der in Fortsetzung der antiken Fiskalmult mit direkten Geldleistungen zu besänftigen war. Daß diese Abgaben in Rom ausschließlich dem Erhalt der Stadtmauern dienen sollten, belegt eine Serie von Senatsurkunden mit der spezifisch erweiterten Poenformel, die im Jahr 1186 mit der ersten an den Senat zu leistenden Buße nach dem Frieden von Konstanz einsetzt. ${ }^{16}$ Dazu angeregt hatte vielleicht auch eine Bestimmung Kaiser Justinians, nach der ein Drittel der städtischen Einnahmen für den Mauerbau aufzuwenden war. ${ }^{17}$

Die Ausstattung der Stadtmauern besaß also Priorität im städtischen Finanzhaushalt. Alle einschlägigen Senatsurkunden des 13. Jahrhunderts griffen, unabhängig vom Inhalt, den Verwendungszweck der Strafgelder explizit auf: Die Hälfte stand jeweils demjenigen zu, dessen Rechte zu schützen waren, die andere Hälfte ging zweckgebunden an den Senat. ${ }^{18}$ Eine besonders lukrative Einnahme-

15 MGH Const. I, Nr.293, S.412, §1: „regalia et consuetudines vestras tam in civitate quam extra civitatem [...] extra vero omnes consuetudines sine contradictione exerceatis, quas $\mathrm{ab}$ antiquo exercuistis vel exercetis: scilicet in fodro et nemoribus et pascuis et pontibus, aquis et molendinis, sicut ab antiquo habere consuevistis vel habetis, in exercitu, in munitionibus civitatum, in iurisdictione, tam in criminalibus causis quam in pecuniariis, intus et extra". Allgemein zu diesem Frieden vgl. u.a. Alfred Haverkamp, Der Konstanzer Friede zwischen Kaiser und Lombardenbund (1183), in: Kommunale Bündnisse Oberitaliens und Oberdeutschlands im Vergleich, hg. von Helmut Maurer, Sigmaringen 1987 (Vorträge und Forschungen 33), S.11-44 mit weiterer Literatur; La pace di Costanza 1183. Un difficile equilibrio di poteri fra società italiana ed impero. Convegno internazionale Milano-/Piacenza, 27-30 aprile 1983, Bologna 1984 (Studi e Testi di storia medioevale 8). Zur Mauer als Sinnbild vgl. u.a. Wolfgang Braunfels, Mittelalterliche Stadtbaukunst in der Toskana, 4. korrigierte und erweiterte Auflage, Berlin 1979, S.45-85.

16 Bartoloni, Codice diplomatico (wie Anm.1), Nr.40: „pro refectione huius inclite Urbis murorum".

17 Cod.Just. VIII.11.11.

18 Angewandt bei der Investitur eines Klosters mit Besitzungen, bei der Annulierung einer Zeugenbefragung, bei der Verurteilung von Bürgern zur Rückerstattung von Geldern, 
quelle war das 1231 im Gefolge der päpstlichen und kaiserlichen Gesetzgebung erlassene Häretikeredikt, nach dem nicht nur die festgesetzte Strafe von 200 Mark, sondern auch ein Drittel der konfiszierten Güter für die Stadtbefestigung zu verwenden war. ${ }^{19}$ Unter Senator Angelo Malabranca flo $\beta$ die eingangs zitierte Poenformel 1235 auch in die Friedensverträge mit Papst Gregor IX. ein, in denen sich die Stadt nach erbitterten Kämpfen wieder der päpstlichen Oberhoheit unterstellte. ${ }^{20}$ Sogar einige der spärlich erhaltenen kirchlichen Schiedssprüche zeigen, daß bei privaten Streitigkeiten die ausgesetzte Vertragsstrafe nicht immer ausschließlich an die vertragsbrechende Partei, sondern in Einzelfällen auch zur Hälfte an den Senat für den Erhalt der Stadtmauer fließen sollte. Beispiele liefern das 1224 in Anwesenheit eines senatorischen Iustitiars gefälte Urteil des Presbyters Bartholomeus von S. Lorenzo im Streit um Bauarbeiten im Bereich der Kirche S. Salvatore in Gallia ${ }^{21}$ und der im Jahre 1258 erlassene Gerichtsentscheid in den Auseinandersetzungen zwischen den Brüdern Curtabraca und Petrus de Vico um den Besitz von Gütern und Kastellen am Lago di Bracciano sowie um einen Turm in der stadtrömischen Rione Parione..$^{22}$

Insgesamt dürften die Stadtmauern wohl nach der Gründung der Kommune einen zunehmend höheren Stellenwert im Bewußtsein der Stadtbewohner errungen haben; zumindest lassen dies auch die Forschungen von Étienne Hubert zum städtischen Raum vermuten. ${ }^{23}$ Bis zur Mitte des 12 .Jahrhunderts waren, nach den Formulierungen der Notariatsinstrumente zu urteilen, weitgehend nur die Tore wahrgenommen worden, die als päpstliche Zollstellen das Leben der Städter merklich beeinflußten, weil hier Steuern für die Erträge aus den umliegenden Anbaugebieten zu entrichten waren; das gigantische Befestigungswerk selbst war an vielen Stellen dem fortschreitenden Verfall preisgegeben. Der Mentalitäts-

bei der Bestätigung von Privilegien und einem Handelsverbot für den Eingangsbereich der alten Basilika von St. Peter; vgl. Bartoloni, Codice diplomatico (wie Anm.1), Nr.55 von 1201: "medietas cuius in refectionem huius inclite Urbis murorum erogetur"; ibid., Nr.68 von 1212: „cuius medietas sit senatus pro muris Urbis“; ibid., Nr.70 von 1214: „alia medietas sit senatus pro muris Urbis“; irbid., Nr.108 von 1244: „et alia [medietas] nurorum Urbis refectionibus applicetur" und „cuius medietas sit murorum Urbis“. Bartoloni, Codice diplomatico (wie Anm.1), Nr.74: „ducentarum marcarum murorum Urbis refectionibus applicandam" und ,tertia murorum Urbis refectionibus deputetur".

20 Bartoloni, Codice diplomatico (wie Anm.1), Nr.81 von 1235: „si quis vero contra facere temptaverit, iram senatus graviter incurrat et odium et insuper solvere teneatur senatui centum libras auri pro muris Urbis"; vgl. ibid., Nr.83.

21 Ingrid Baumgärtner, Regesten aus dem Kapitelarchiv von S.Maria in Via Lata (12011259), Teil1 und 2, in: Quellen und Forschungen aus italienischen Archiven und Bibliotheken 74 (1994) S.42-171 und 75 (1995) S.32-177, hier Teil1, Regest 127.

22 Archivio di Stato di Roma (im weiteren: ASR), cass. 59: Ospedale di S. Spirito in Sassia, perg. 8 vom Juni 1258: „sub compromissa pena mille marcharum boni argenti ab utraque parte ad invicem promissa pro medietate [sen]atui pro muris Urbis applicanda et pro alia medietate parti fidem servanti a parte infideli prestanda". Vgl. Hubert, Espace urbain (wie Anm. 8), S.64-70. 
wandel vollzog sich nach der Erneuerung des Senats: Die Wiederherstellung von Stadtmauern und Brücken wurde zum bedeutungsvollen Zeichen kommunaler Machtentfaltung, auch wenn die Finanzierung offensichtlich nicht immer einfach und die Mitwirkung jedes einzelnen zwingend notwendig war.

$\mathrm{Da} B$ die Mauer im Denken der Bürgerschaft weiterhin einen erheblichen Stellenwert einnahm, beweisen zudem testamentarische Verfügungen mit entsprechenden Legaten zugunsten einer Renovierung. ${ }^{24}$ An der angegebenen Regelungskompetenz wurde wohl bis ins 14.Jahrhundert festgehalten, wenngleich die wenigen aus dem 13.Jahrhundert erhaltenen legislativen Akte, soweit überhaupt bekannt, keinerlei städtische Bauaktivitäten anklingen lassen. ${ }^{25}$ Es war wohl nicht im Sinne der längst wieder erstarkten, rivalisierenden Adelsfraktionen, mit allzu genauen Vorschriften zur Bauplanung individuelle Freiheiten zu beschränken. Aber die Verankerung der gemeinsamen Verteidigungsaufgabe im Stadthaushalt war inzwischen wohl so selbstverständlich geworden, da $B$ die ersten überlieferten städtischen Statuten von 1363 nur noch allgemein und ohne Angabe eines Verwendungszwecks betonten, daß die Hälfte aller 100 Soldi übersteigenden Strafgebühren an die städtische Kammer abzuführen wäre. ${ }^{26}$

Erst diese gegen die Vorherrschaft der Barone entworfene Statutenkompilation einer kommunalen Regierung, der ein einzelner, von auswärts berufener Senator vorstand, reglementierte zahlreiche Details der städtischen Infrastruktur, wobei nicht übersehen werden darf, daß von den früheren, nach der Übersiedelung der Päpste nach Avignon versuchten Verfassungsreformen nur die Statutenfragmente von 1305 und 1316 erhalten sind, ${ }^{27}$ die uns über mögliche Normierungsbestrebungen im öffentlichen Bauwesen nicht unterrichten. Intention dieser Statutenkodifikation war die Ausübung scharfer Kontrollen zur Verbesserung der Sicherheit in der Stadt: Normative Verfügungen regelten die Instandhaltung aller öffentlichen Straßen und Brücken innerhalb und außerhalb der Stadt, für die der eidlich verpflichtete Senator ohne Ausnahmen und Verzögerungen rücksichtslos zu sorgen hätte. Vorrangiges Ziel war die freie Befahrbarkeit und Zugänglichkeit der Straßen und Brücken der Gemeinschaft. Es

24 G. Ferri, Le carte dell'archivio Liberiano dal secoloX al XV, in: Archivio della R. Società romana di storia patria 27(1904) S.147-202 und S.441-459, 28(1905) S.23-39 und 30(1907) S.119-168, hier Regest Nr.63, S.123-124 mit dem Testament eines Bartholomeus vom 26. April 1266, Original in der Biblioteca Apostolica Vaticana, Archivio di S.Maria Maggiore, cart.66, perg.63; Felice.Nerini, De templo et coenobio SS.Bonifacii et Alexii historica monumenta, Roma 1752, Appendix, Nr.35, S.445ff. mit dem Testament von Crescentius, Sohn des Leo Iohannis Iudicis, vom 30.September 1271, Original im ASR, cass.2: SS. Alessio e Bonifazio, perg.10; zu beiden Testamenten vgl. Robert Brentano, Rome before Avignon. A Social History of Thirteenth-Century Rome, London 1974, S.280.

25 Zur Gesetzgebung genauer Baumgärtner, Die normativen Grundlagen des Rechtslebens (wie Anm.11), S.21-26.

$26 \mathrm{Re}$, Statuti della città di Roma (wie Anm.6), S.122f., Lib.2, cap.LXX.

27 Vgl. Baumgärtner, Die normativen Grundlagen des Rechtslebens (wie Anm.11), S. 26. 
wurde strengstens verboten, die Fahrwege durch Gebäude, Tore, Vorbauten („porticalia“) oder andere Absperrungen („apparamenta“) zu blockieren; bereits errichtete Bauten waren auf Kosten ihrer Erbauer oder besser „Belagerer" zu beseitigen und zu zerstören. ${ }^{28}$

Diese Pflicht zur Freihaltung aller öffentlichen Hauptstraßen, Straßen in Stadtteilen und Gassen wird in den Statuten mehrfach wiederholt, wobei die Buße jeweils zur Hälfte an die städtische Kammer und an den Ankläger fließen sollte. ${ }^{29}$ Der Senator und alle kapitolinischen Amtsträger müßten alle Tore, Gitter und sonstige Absperrungen auf öffentlichen Straßen innerhalb der Stadt einreißen lassen, um freien Durchgang zu gewährleisten und Besetzungen oder Blockaden zu verhindern. Den Missetätern drohten bei Widerspruch und mangelndem Gehorsam hohe, nach ihrer sozialen Stellung gestaffelte Bußen, und zwar die beachtliche Summe von 100Mark Silber für die nobiles und magnates, also die baronale Feudalaristokratie mit ausgedehnten signorialen Herrschaften, hingegen $100 \mathrm{Libbra}$ Provisini für milites oder cavallarotti, also die unteren Ränge einer stadtrömischen Oberschicht und reiche Bürger, die der städtischen Miliz zu Pferd dienten, sowie die Hälfte für einen pedes, also das gesamte restliche Volk. Diesem war auch die aufsteigende Mittelschicht zuzurechnen, soweit die wohlhabenden Händler, führenden Handwerker, Bankiers, Kaufleute und bovattieri, also Viehzüchter, Großbauern, Grund- und Immobilienbesitzer, nicht zu den berittenen Streitkräften zählten. ${ }^{30}$ Insbesondere die Gruppen der cavallarotti und

${ }^{28} \mathrm{Re}$, Statuti della città di Roma (wie Anm. 6), S.190, Lib.2, cap. CXCVI: „De edificantibus in viis comunis et pontibus. Senator teneatur vinculo sacramenti ad penam .c. librarum prov. precise omni exceptione et dilatione remota cum effectu expediri et excommorari omnes vias publicas et pontes, infra Urbem et extra, et si qua edificia opera hostia porticalia seu quaecumque alia apparamenta facta sint vel facta apparent in hiis viis et pontibus, per quascumque personas cum effectu, omni exceptione et dilatione remota faciat tolli destrui et demoliri expensis illorum qui in predictis viis et pontibus edificaverunt seu edificari fecerunt et de dicta edificatione vel occupatione facta dictarum rerum et pontium per quem seu per quos predicta edificatio seu occupatio fuerit facta stetur sacramento conquerentis de predictis seu denumptiantis predicta cum probatione publice fame. Et hoc semper inquirere teneatur."

29 Re, Statuti della città di Roma (wie Anm.6), S.160, Lib.2, cap. CXXXV: „De viis non apparandis. Nullus apponat aliquid seu apponi faciat in aliqua via comuni publica seu vicinali vel viculo nec apparet nec apparari faciat in aliqua ipsarum viarum, et qui contrafecerit viam ipsam liberare et disparare teneatur, et nichilominus solvat .x. libras prov. nomine pene de qua pena medietas sit Camere, et alia medietas accusantis.“

30 Re, Statuti della città di Roma (wie Anm. 6), S. 161, \$1. zu Lib. 2, cap. CXXXV: „Senator et omnes singuli officiales capitolii domini senatoris teneantur vinculo sacramenti facere distrui et funditus dirrui omnes portas et omnia cancella et apparata actenus facta in viis publicis intus civitatem romanam, et ipsas vias publicas facere aperiri et liberas permanere et non permictant de cetero ipsas vias occupari vel apparari sive claudi per aliquam personam. Et si Senator fuerit negligens in predictis et officiales predicti solvant de eorum salario nomine pene iiiior libras prov. et quicumque contradixerit predicta fieri ad mandatum predictorum Senatoris et eorum officialium ac eisdem non obedierit solvat 
bovattieri waren führend am popolaren Regiment beteiligt, das sich auf die für Barone und Magnaten nicht zugängliche städtische Miliz stützte, deren vier Vorsteher zusammen mit sieben Reformatoren und zwei banderesi den consiglio privato, das oberste Entscheidungsgremium, bildeten.

Die Zielsetzung solcher Maßnahmen gegen die Macht der selbstherrlichen Barone war, die öffentliche Sicherheit nicht nur innerhalb der Stadtmauern, sondern auch im städtischen Distrikt zu gewährleisten. So wurde den untergebenen Gemeinschaften, seien es Städte, castra oder andere Orte, der Auftrag erteilt, die Straßen im Distrikt sorgfältig zu bewachen oder bewachen zu lassen, um den Reisenden sicheren Zugang zur Stadt zu ermöglichen, ohne daß sie von zweifelhaften Gestalten, Räubern oder Menschen von schlechtem Ruf belästigt würden. ${ }^{31}$ Alle Gemeinschaften in der näheren Umgebung hatten sich an dieser Sicherung öffentlicher Wege und Straßen zu beteiligen. ${ }^{32}$ Strikt verboten war ferner, zumindest für die Straßen von Tivoli, das Werfen von Steinen aus Türmen und Häusern im Streit oder Kampf zwischen befeindeten Nachbarn. ${ }^{33}$ Sol-

nomine pene .c. marchas argenti Camere Urbis, pro medietate Camere Urbis et pro alia medietate accusanti. Et nichilominus predicta ducere teneatur ad effectum. Et predicta locum habeant in nobilibus et magnatibus. Si autem fuerit miles vel de genere militum vel cavallaroctus vel habitus pro cavallarocto contradicens solvat .c. libras. Si vero, pedes .1 . libras prov. solvat." Zur Schicht der Barone und Magnaten vgl. Sandro Carocci, Baroni di Roma. Dominazioni signorili e lignaggi aristocratici nel Duecento e nel primo Trecento (Collection de l'École Française de Rome 181 und Nuovi studi storici 23), Rom 1993.

$31 \mathrm{Re}$, Statuti della città di Roma (wie Anm.6), S.161, Lib.2, cap.CXXXVI: „De comunitatibus debentibus custodire stratas. Comunitates civitatum castrorum et aliorum locorum de districtu Urbis stratas et tenimenta ipsorum diligenter faciant custodiri ut itinerantibus per ea sit securus accessus et in dictis civitatibus castris vel locis non receptent diffidatos latrones et homines male fame, ymbo si quos ibidem scientes invenerint comprehendat ad penam ducentarum librarum prov. pro quolibet receptatore et pro qualibet vice." Zur kommunalen Kontrolle der Sicherheit auf öffentlichen Straßen vgl. Szab6, Comuni e politica stradale (wie Anm.7), S.118-135.

32 Re, Statuti della città di Roma (wie Anm. 6), S.188, Lib.2, cap. CXCII: „De comunitatibus debentibus actare stratas et vias. Comune et homines castrorum villarum et districtus Urbis teneatur ad penam .c. librarum prov. actare vias publicas et stratas ad hoc ut euntes et redeuntes possint secure et sine periculo ire et reddire et venire, et hoc teneatur fieri facere. Et hoc in principio officii domini Senatoris publice bandiatur infra $\mathrm{x}$. dies sub pena xxv. librarum prov."

33 Re, Statuti della città di Roma (wie Anm. 6), S.180, Lib.2, cap. CLXXVI: „De lapidantibus de turribus et domibus tyburtinis. Si fuerit lapidatum, seu proiecti lapides de aliqua domo vel turri civitatis tyburtine in aliqua rissa vel bactalia contra aliquem convicinum aut inimicum domini dicte domus vel turris aut contra quamcunque aliam personam, quod teneatur dominus domus vel turris ad illam penam ad quam tenentur romani de quorum domibus vel turribus lapidaretur." Zum Steinewerfen aus Häusern vgl. die entsprechende Passage im ältesten Statutencodex von Tivoli aus dem Jahre 1305, abgedruckt in: Statuti della Provincia Romana, 2Bde., Roma 1910 und 1930 (Fonti per la storia d'Italia 48 und 69), Bd.1: Vicovaro, Cave, Roccantica, Ripi, Genazzano, Tivoli, 
che Bestimmungen waren angesichts der ständigen Fehden zwischen den führenden Familienverbänden in Stadt und Umland offensichtlich mehr als notwendig, um die wirtschaftlichen Interessen der wohlhabenden Schichten des regierungstragenden ,Popolo' zu verteidigen.

Ein heikles Problem der städtischen Infrastruktur war zudem die städtische Wasserversorgung. ${ }^{34}$ Die antiken Aquädukte mußten durch die Jahrhunderte hindurch immer wieder in zeitraubender, kostenintensiver Arbeit repariert und die Wasserläufe einiger lebenswichtiger Bäche überwacht werden, auch wenn entsprechende kommunale Rechtsvorschriften erst aus der Statutensammlung von 1363 bekannt sind. Die Sorge der Gesetzgeber galt unerlaubten Abzweigungen im unter- und oberirdischen Rohrsystem. Sie verfügten, daß Richtungsänderungen von Bächen zu melden und der frühere Verlauf auf Kosten des Verursachers wiederherzustellen wärer.$^{35}$ Genauere Anweisungen erteilten sie ferner für einzelne, im römischen Alltagsleben unentbehrliche Wasserläufe, speziell für die bei der Porta Metronia in die Stadt fließende aqua marane, deren Verlauf mit allen Besonderheiten beschrieben wurde, um vorübergehende Abweichungen des Bachlaufes und die einzelnen Bürgern zustehenden Privilegien festzuschreiben. Diese Kontrolle war um so schwieriger, da die flachen Wasserarme im sumpfigen Gelände zwischen den beiden Hügeln Palatin und Aventin ihren Lauf immer wieder änderten und nur die Trockenlegung eine gewisse Verfestigung versprach. Die Bedeutung dieses vielseitig für Hygiene, Ernährung, Energieproduktion und Transport verwertbaren Wasserlaufes war so gro $\beta$, daß jeder neue Senator mit seinen städtischen Konservatoren im ersten Monat seiner Regierung zur Besichtigung und Überprüfung anzutreten hatte. ${ }^{36}$

Castel Fiorentino, hg. v. Francesco Tomassetti/Vincenzo Federici/Pietro Egidi, S.135301, hier S.212, cap. CLXXVII.

34 Einen guten Überblick über die Probleme der Wasserversorgung im Mittelalter gibt u.a. der auf Mittel- und Westeuropa konzentrierte Sammelband Die Wasserversorgung im Mittelalter, hg. v. der Frontinus-Gesellschaft e.V. (Geschichte der Wasserversorgung 4), Mainz 1991; unsystematisch zusammengestellte Quellenausschnitte zum Thema bieten Günther Binding/Susanne Linscheid-Burdich, Planen und Bauen im frühen und hohen Mittelalter nach den Schriftquellen bis 1250, Darmstadt 2002, S.593-605; zu den römischen Aquädukten vgl. Hubert, Espace urbain (wie Anm.8), S.75-79; Krautheimer, Rom. Schicksal einer Stadt (wie Anm. 8), S.278f. und passim.

$35 \mathrm{Re}$, Statuti della città di Roma (wie Anm.6), S.186, Lib.2, cap. CLXXXVIII: „De aqua circhuli et aliis aquis. Aqua circhuli vaddat per cursum suum et nullus detineat nec detineri faciat ipsam aquam ab antiquo cursu in aliqua parte sui, et qui contrafecerit solvat pro pena .l. libras prov. de qua pena medietatis sit camere et alia medietas accusatoris. Et idem fiat in omnibus cursibus aquarum, de hoc quilibet accusare et denumptiare possit, et nichilominus teneatur talis dominus aquam redducere in pristino cursu suis expensis."

$36 \mathrm{Re}$, Statuti della città di Roma (wie Anm.6), S.187, Lib.2, cap.CLXXXIX: „De aqua marane. [...] Et quod senator et conservatores Urbis qui per tempora erunt primo mense eorum regiminis teneantur mictere ad videndum dictas aquas et eorum cursus pro observatione predictorum, sub pena .xxv. librarum applicandarum camere Urbis.“ 
Eine besondere Sorge der Gesetzgeber galt der Instandhaltung der noch bestehenden antiken Aquädukte, für die eigene Amtsträger, die marescalci curie capitolii, zuständig waren. Im Zentrum der Aufmerksamkeit stand das die dicht besiedelte Innenstadt versorgende Aquädukt der Aqua Vergine oder Forma Virgo, das von der Porta Salaria aus in dem Brunnen endete, aus dem sich später die Fontana di Trevi entwickeln sollte („fontis et aque trivii"). Keiner durfte es wagen, am streng kontrollierten, über große Strecken unterirdisch verlaufenden Aquädukt einen Wasserhahn oder ein einfaches Loch anzubringen, um Wasser in eingezäunte Areale und Pferche umzuleiten. ${ }^{37}$ Für die regelmäßig anfallenden Reparaturarbeiten waren vier geeignete und vertrauenswürdige Männer heranzuziehen, die Rechenschaft über die geleisteten Arbeiten abzulegen und den ganzen Monat Oktober für die Instandsetzung aufzuwenden hatten; zwei dieser Männer sollten aus der Rione Trevi, zwei aus der Rione Colonna, also offensichtlich den beiden vorrangig belieferten Rioni, stammen. ${ }^{38}$ Zudem wurden alle Anlieger verpflichtet, entstehende Risse ("spiralglia“) bis zur Ausbesserung zu schließen, damit kein Regenwasser in das Aquädukt eindringen konnte. ${ }^{39}$

Normative Vorschriften zu Renovierung und Schutz von Stadtmauern und Brücken, zur Instandsetzung von Hauptstraßen und Wasserleitungen waren klare Zeichen kommunaler Selbstbehauptung und angestrebter Machtentfaltung. Der Anspruch des römischen Senats auf das Befestigungsrecht und die Kontrolle der Zufahrtsstraßen läßt sich unmittelbar nach dem Einsetzen der kommunalen Überlieferung erkennen. Die öffentliche Bekanntmachung in Inschriften und in Urkundenformeln half nachfolgenden Senatoren, die ausgeübte Macht im Bewußtsein der Stadtbewohner und Vertragspartner zu verankern. Eine weitere Differenzierung zeigt sich in der gegen die Magnaten gerichteten statuarischen Gesetzgebung des 14.Jahrhunderts; sie konzentriert sich im Sinne des Gemeinwohles auf die Instandhaltung und Sicherung der von individuellen Herrschaftsansprüchen bedrohten Qualität der Zufahrtswege, Brücken und Wasserleitungen.

Vgl. Pasquale Adinolfi, Roma nell'età di mezzo, Roma 1881, ND Firenze 1980, S.155163, zur Aqua Crabra, die im Mittelalter Marana genannt wurde, bes. S.155-157.

37 Re, Statuti della città di Roma (wie Anm.6), S.264-265, Lib.3, cap. CXXVI (CXXIV): "Quod marescalci curie capitolii sint patarentes et curam habeant aque fontes trivii."

$38 \mathrm{Re}$, Statuti della città di Roma (wie Anm.6), S.265, §2. zu Lib.3, cap. CXXVI (CXXIV): „Item statuimus quod illi vel ille qui essent positi ad actandum et reparandum dictam fontem debeant reddere rationem de introitu et exitu dicte actationis quatuor hominibus ydoneis et discretis quorum duo sint de regione Trivii duo alii de regione Colupne et dictam rationem teneatur et debeant reddere per totum mensem octubris tunc currentis ad penam .c. sollidorum prov."

39 Re, Statuti della città di Roma (wie Anm. 6), S.265, §3. zu Lib.3, cap. CXXVI (CXXIV): „Item dicimus et ordinamus quod omnes homines in vineis eorum spiralglia aque fontis trivii debeant remundare usque ad refectum ita quod aqua pluvia non possit intrare in dicta forma“. 


\section{Schutz antiker Monumente als Gradmesser für Stadtqualität}

Die Ruinen antiker Monumente prägten im Hochmittelalter das Erscheinungsbild Roms. Als integraler Bestandteil des Alltagslebens erinnerten sie allgegenwärtig an die klassische Vergangenheit. Ursprünglich „öffentliche“ Gebäude waren längst in Privat- oder Kirchenbesitz übergegangen. Die Kapitelle, Pfeiler, Statuen und Steinblöcke, die im 12.Jahrhundert als antikes Plündergut ihre Besitzer wechselten, wurden in der Forschung vorwiegend unter dem Aspekt der Wiederbelebung der Antike betrachtet. ${ }^{40}$ Zudem boten sie Anlaß für innerrömische Kompetenzstreitigkeiten und gesetzgeberische Maßnahmen. Der Papst beanspruchte Gebäude wie die Engelsburg und das zur Kirche S.Maria della Rotunda umfunktionierte Pantheon. Kirchen und Konvente hatten Besitz ergriffen von den Trümmern des Portikus der Octavia westlich des Marcellustheaters, dessen Säulenfront die Kirche S. Angelo in Pescheria als Eingang nutzte, vom Triumphbogen des römischen Kaisers Septimius Severus auf dem Forum, an den die Titelkirche SS. Sergio e Bacco angebaut war, von den dreistöckigen Kolonnaden des Septizonium Divi Severi am Rande des Palatin, das die Mönche von S. Gregorio Magno (auch SS. Andrea e Gregorio in Clivo Scauri) früh zur Festung verwandelt hatten ${ }^{41}$ und von den Thermen des Caracalla, die sich die Dominikanerinnen von S.Sisto angeeignet hatten. Römische Adelsfamilien erbauten ihre eigentümlichen Festungen in und auf herrenlosen Ruinen, wie beispielsweise die Frangipani im Kolosseum und die Savelli im Marcellustheater. Von allen Parteien umkämpft war das antike Hadriansmausoleum, das im Mittelalter als stark befestigtes Castel S. Angelo strategisch überaus bedeutsam den Flußübergang zwischen Tiberknie und der Leostadt überwachte. Und der römische Senat versuchte bald nach seiner Erneuerung, Anrechte in der Zone um das Kapitol geltend zu machen und in die innerrömische Antikenaufteilung gestaltend einzugreifen.

Einen faktischen Anspruch auf die Vergabe antiker Reste erhob der Senat spätestens im Jahr 1162, als er das Benediktinerinnenkloster SS. Ciriaco e Niccolò in Via Lata mit der Traianssäule (Karte), die sich im Besitz der Pfarrkirche SS. Apostoli befand, urkundlich investierte und bei Beschädigung der Säule wie bei einem Majestätsverbrechen mit Todesstrafe und Konfiskation der Güter

40 Zum Umgang der Kommunen mit der Antike vgl. u.a. Norberto Gramaccini, Mirabilia. Das Nachleben antiker Statuen vor der Renaissance, Mainz 1996, bes. S. 82-97 und 159185. Zur Begrifflichkeit für römische Überreste in mittelalterlichen Dokumenten vgl. Arnold Esch, Antike in der Landschaft: Römische Monumente in mittelalterlichen Grenzbeschreibungen um Rom, in: Cecil L.Striker (Hg.), Architectural Studies in Memory of Richard Krautheimer, Mainz 1996, S.61-65.

$41 \mathrm{Vgl}$. Alfonso Bartoli, I documenti per la storia del Settizonio Severiano e i disegni inediti di Martin van Heemskerck, in: Bollettino d'Arte 3(1909), S.253-269; Hubert, Espace urbain (wie Anm.8), S.81 und 138. Allgemein dazu vgl. Krautheimer, Rom. Schicksal einer Stadt (wie Anm.8), passim. 
drohte. ${ }^{42}$ Die Senatsurkunde verfolgte damit in Konkurrenz zum Papsttum zwei konkrete Ziele: den Schutz eines prächtigen antiken Monuments und die Privilegierung eines bedeutenden Konvents, dem mit der Säule auch die daneben liegende kleine Kirche S.Nicola übertragen wurde. Für einen solchen Antikenschutz gab es bereits ein älteres kirchliches Vorbild: Eine nach Form einer Urkunde aufgebaute Inschrift im Atrium des Klosters S. Silvestro in Capite aus dem Jahre 1119 garantierte dem Konvent den Besitz der Säule Marc Aurels, der „columpna Antonini“ “ ${ }^{43}$ Handfeste Vorteile waren damit verbunden: Die prächtige Säule, ursprünglich der Traianssäule nachgebaut, überragte das umliegende Gebiet und bot den Pilgern eine großartige Aussicht, die sie durch reichliche Opfergaben am eigens dafür errichteten oberen Altar entlohnen mußten.

Derartige Privilegien waren keine Seltenheit, auch wenn sie nicht alle so publikumswirksam zur Schau gestellt wurden. Papst InnocenzIII. bestätigte beispielsweise 1199 der Titelkirche SS. Sergio e Bacco am Kapitol, die er bereits als Kardinal verwaltet und ausgestattet hatte, die Hälfte des Triumphbogens des römischen Kaisers Septimius Severus, die andere Hälfte diente Römern als Wohngebäude. Zumindest auf der Kirchenseite steigerten Anbauten, wie ein darauf stehender Festungsturm und angebaute Kemenaten, die Zweckdienlichkeit des Besitzes, ${ }^{44}$ dessen strategische Bedeutung aus seiner Nähe zu gern genutzten Versammlungsplätzen von Senat und Kirche resultierte. Von hier aus zu überwachen waren immerhin der vom Kapitol zum Forum hinabführende

42 Bartoloni, Codice diplomatico (wie Anm.1), Nr.18, S.25-27, Original: Biblioteca Apostolica Vaticana, Archivio di S.Maria in Via Lata, cass.317, perg.1. Vgl. Ingrid Baumgärtner, Geschichtsbewußtsein in hochmittelalterlichen italienischen Privaturkunden, in: Hans-Werner Goetz (Hg.), Hochmittelalterliches Geschichtsbewußtsein im Spiegel nichthistoriographischer Quellen, Berlin 1998, S.269-292, hier S.282f.; dies., Rombeherrschung und Romerneuerung. Die römische Kommune im 12.Jahrhundert, in: Quellen und Forschungen aus italienischen Archiven und Bibliotheken 69(1989), S.27-79, hier S.37-39; Karl Noehles, Die Kunst der Cosmaten und die Idee der Renovatio Romae, in: Festschrift Werner Hager, hg. von Günther Fiensch/MaxImdahl, Recklinghausen 1966, S.17-37, hier S.29; Arnold Esch, Spolien. Zur Wiederverwertung antiker Baustücke und Skulpturen im mittelalterlichen Italien, in: Archiv für Kulturgeschichte 51(1969), S.1-64, hier S.32f.; Norberto Gramaccini, La prima riedificazione del Campidoglio e la revoluzione senatoriale del 1144, in: Roma, centro della cultura dell'Antico nei secoli XV e XVI. Da Martino V al Sacco di Roma 1417-1527, Atti del Convegno Internazionale, Roma 1989, S.33-47, hier S.43, revidierte deutsche Fassung als Unterkapitel in: Gramaccini, Mirabilia. Das Nachleben antiker Statuen (wie Anm.40), hier S.185.

43 Gregorovius, Geschichte der Stadt Rom (wie Anm.9) Buch VIII, Kap.7.4, Ausg. 1978, Bd.II,1 S.286. Vgl. Forcella, Iscrizioni delle chiese (wie Anm.9), Bd.9, Roma 1877, S.79 Nr.149: „Siquis ex hominibus columpnam per violentiam a nostro monasterio subtraxerit, perpetue maledictioni sicuti sacrilegus et scarum rerum invasor subiaceat et anathematis vinculo perpetuo teneatur fiat."

44 Vgl. den Urkundentext bei Othmar Hageneder/Werner Maleczek/Alfred A.Strnad, Die Register InnocenzIII., Bd. 2: 2. Pontifikatsjahr, Rom/Wien 1979, Nr.94, S. 198. 
Steilpfad, die in der antiken Curia Iulia etablierte Diakoniekirche S.Adriano, deren Gebäude bis in die Zeit Theoderichs als Tagungsstätte des antiken Senats gedient hatten, ${ }^{45}$ sowie die in den Ruinen des antiken Secretarium Senatus eingebaute Kirche SS. Martina e Luca am Forum, Ausgangspunkt der seit Beginn des 8. Jahrhunderts stattfindenden päpstlichen Purificatio-Prozession nach S.Maria Maggiore und spätestens seit 1185 wieder Versammlungsort der Richter. ${ }^{46}$ Der Bogen war somit ein für alle Senatsbelange wichtiger Punkt, neben dem sich zudem der umbilicus Urbis, eine in der antiken Kaiserzeit aus Ziegeln gebaute Konstruktion zur Kennzeichnung der angeblichen Stadtmitte, befand.

Die Liebe der Römer zu ihren antiken Schätzen basierte auf deren Schönheit und auf deren Verwertbarkeit, die der Senat in Konkurrenz mit dem Papsttum verteidigte, auch wenn sich eine eigenständige, von der Kommune ausgehende Systematik für die Bewahrung der Antike anfangs nicht nachweisen läßt. Zum Ausdruck eines innerrömischen Machtanspruchs wurde dieses Vorgehen spätestens dann, wenn das Privileg einem Benediktinerinnenkloster nützte, das im Ringen um die Macht in Rom eine wichtige Rolle spielte.

Der Schutz antiker Bauten setzt sich im großen Statutenwerk von 1363 fort. Im zweiten Buch wird streng untersagt, antike Bauwerke innerhalb der Urbs zu zerstören oder zerstören zu lassen. Zwei Gründe werden dafür benannt: Erstens sollte die Stadt nicht durch zurückbleibende Ruinen entstellt werden, zweitens würden die antiken Gebäude die reiche Ausstattung der Stadt, den decorem Urbis, öffentlich zur Schau stellen. Beide Argumente zeigen das spezielle Ziel des römischen Denkmalschutzes, nämlich die wertvolle Substanz der vergangenen Stadt für die Gegenwart zu nutzen und deren eigene Schönheit zu bewahren. ${ }^{47}$ Sie erinnern zugleich an die grandiosen, republikanische Größe und Freiheit heraufbeschwörenden Ideen des von Mai bis November 1347 Rom beherrschenden Tribunen Cola di Rienzo, des großen Widersachers der römischen Barone, der durch eine mitreißende Rhetorik fasziniert und den Stolz der wehrhaften Bürger auf ihre Vergangenheit entzündet hatte; für Teile des nur idealty-

45 Gerhard Wolf, Salus Populi Romani. Die Geschichte römischer Kultbilder im Mittelalter, Weinheim 1990, S. 49 und S.394 mit Abb.33;Nine Robijnte Miedema, Die römische Kirche im Spätmitterlalter nach den ,Indulgentiae ecclesiarum urbis Romae' (Bibliothek des Deutschen Historischen Instituts in Rom 97), Tübingen 2001, S439-445.

46 Bartoloni, Codice diplomatico (wie Anm.1), Nr.39; Chr. Huelsen, Le chiese di Roma nel Medio Evo, cataloghi ed appunti, Florenz 1927, ND New York/Hildesheim 1975, S.381, Nr.107; vgl. Wolf, Salus populi romani (wie Anm.45), S. 49 und 57.

47 Re, Statuti della città di Roma (wie Anm.6), S.188, Lib.2, cap.CXCI: „De antiquis edificiis non diruendis. Ne ruynis civitas deformetur et ut antiqua edificia decorem Urbis publice representent, statuimus quod nullus sit ausus aliquod antiquum edificium Urbis diruere vel dirui facere intra Urbem ad penam .c. librarum prov., cuius pene medietas sit Camere et alia medietas sit accusantis. Et Senator teneatur ad hoc inquirere nec dominus Senator vel aliquis alius possit dare licentiam contra predicta et si dederit incidat in pena .c. florenorum auri, camere applicandorum, et nichilominus licentia data non valeat." 
pisch vereinigten Popolo war er - etwa der wohl zwischen Herbst 1354 und Frühjahr 1358 niedergeschriebenen Chronik des Anonymus Romanus zufolge ${ }^{48}$ die Verkörperung eines römischen Traumes geblieben, obwohl er sich 1354, nachdem er von Kardinal Aegidius Albornoz erneut als Senator eingesetzt worden war, nur noch mit brutaler Gewalt für wenige Monate behaupten konnte.

Über die kommunale Regierung, die immer noch Rienzos Bestrebungen verpflichtet war, fanden solche Gedanken wieder Eingang in die Gesetzgebung von 1363. Selbst der Tag seiner Erhebung im Jahre 1347, der 20. Mai, wurde nun zum städtischen Festtag deklariert und sollte mit einer verschwenderisch ausgestatteten Messe in der kommunalen Kirche S. Maria in Aracoeli begangen werden. ${ }^{49}$ Deshalb richteten sich die im Statut verhängten Strafen für Antikenvandalismus auch nicht nur gegen die Zerstörer der Bauten, sondern der Antikenschutz wurde weiter abgesichert. Unter der immensen Auflage von 100 Goldflorenen, zahlbar an die städtische Kammer, mußte jeder Senator beschwören, jegliche Anzeige genau $\mathrm{zu}$ verfolgen und keine Ausnahmegenehmigung, die ohnehin keine Gültigkeit besäße, zu erteilen. In der popolaren Stadtordnung ist dies allerdings das einzige Statut, das ausdrücklich den antiken Baubestand verteidigt. Vage an den Antikengedanken knüpft vielleicht noch das Verbot des Ausgrabens von Grenzsteinen und Objekten auf fremdem oder öffentlichem Besitz an, dessen Durchsetzung immerhin mit der Amputation der rechten Hand nachgeholfen werden sollte, wenn die nach Standeszugehörigkeit differenzierte Geldstrafe nicht bezahlt wurde..$^{50}$

Eine ähnliche Unterstützung genoß sonst nur noch die sakrale Ausstattung der Stadt, die Alfred Haverkamp gemeinhin als "Gradmesser für die Stadtqualität" bezeichnet hat. ${ }^{51} \mathrm{Daß}$ solche Schutzbestimmungen in Rom eine längere Tradition besessen haben müssen, zeigt das eindringliche statutarische Verbot, mit einem Bogen, Wurfmaschinen oder einfachen Steinen auf die wertvollen Glasfenster der Klosterkirche S.Maria in Capitolio und aller anderen Kirchen zu zielen. $^{52}$ Die kapitolinische Kirche und ihr Konvent hatten nicht nur sakralen

48 Zum Zusammenhang vgl. Gustav Seibt, Anonimo Romano. Geschichtsschreibung in Rom an der Schwelle zur Renaissance (Sprache und Geschichte 17), Stuttgart 1992, bes. S. 89-103.

49 Re, Statuti della città di Roma (wie Anm. 6), S.283, Lib.3, cap. CXLIX (CXLVI). Zur Kirche vgl. Miedema, Die römische Kirche (Wie Anmerkung. 45), S. 603-614.

$50 \mathrm{Re}$, Statuti della città di Roma (wie Anm. 6), S.181, Lib.2, cap. CLXXVII.

51 Alfred Haverkamp, „Heilige Städte“ im hohen Mittelalter, in: Mentalitäten im Mittelalter. Methodische und inhaltliche Probleme, hg. v. Františrk Graus, Sigmaringen 1987 (Vorträge und Forschungen 35), S.119-156, hier S.136; übernommen u.a. von Frank G.Hirschmann, Stadtplanung, Bauprojekte und Großbaustellen im 10. und 11.Jahrhundert. Vergleichende Studien zu den Kathedralstädten westlich des Rheins, Stuttgart 1998, S.432-446.

$52 \mathrm{Re}$, Statuti della città di Roma (wie Anm. 6), S.172, Lib. 2, cap.CLI: „De proicientibus cum archu et balista in fenestris vitreis. Statuimus quod nullus homo debeat proicere cum arcu 
Zwecken gedient, sondern zumindest in den Jahren um 1242 auch als städtische Gebäude fungiert, in denen sich der Rat versammelte und vor denen wichtige Erlasse öffentlich verkündet wurden. ${ }^{53}$ Dabei muß die Vorschrift von 1363 aus früheren Statuten übernommen worden sein. Darauf verweisen sowohl die für das neue Regime ungewöhnlich undifferenzierte Strafandrohung, die dem neuen bürgerlichen Ordnungsdenken des Popolo deutlich widersprach, als auch der altmodische Kirchenname; denn die Franziskaner hatten 1250 die alten Bauten übernommen und nach dem Abriß in den späten fünfziger Jahren mit dem Neubau der deutlich größeren Kirche S. Maria in Aracoeli begonnen.

Offensichtlich wurde antiken Monumenten im kommunalen Rom über Jahrhunderte hinweg eine ganz besondere Funktion zugemessen, wenngleich wir nicht wissen, ob und wie die erlassenen Rechtsbestimmungen in dem von Zwietracht und Rauflust geprägten Stadtalltag tatsächlich umgesetzt wurden. Sicher ist nur, daß die innerrömische Konkurrenzsituation und der kommunale Stolz auf die Vergangenheit die Bewahrung der faßbaren Antike in besonderer Weise belebten. Und womöglich läßt sich sogar eine allmähliche Verschiebung der Interessen von der praktischen Verwertbarkeit zur demonstrativ artikulierten Wertschätzung des schönen Dekors in der Mitte des 14. Jahrhunderts erkennen.

\section{Bauaufsicht und Überwachung des Baubestands}

Die zielgerichtete Überwachung des städtischen Baubestands setzte in Rom, wie in anderen Städten, mit dem beginnenden Ausbau des kommunalen Ämterapparats in den zwanziger Jahren des 13. Jahrhunderts ein, als das Amt der von Senat und römischem Volk eingesetzten Magistri aedificiorum erstmals urkundlich faßbar wird und damit die Aufgaben unmißverständlich an eine eigenständige, gut organisierte Kommission delegiert wurden. Laut Dienstbezeichnung sollten die vermutlich weitgehend einer gehobenen Mittelschicht entstammenden Amtsträger die Kontrolle über Häuser, Straßen, Mauern, Plätze und Weinberge innerhalb und außerhalb der Urbs übernehmen. ${ }^{54}$ Dieses Streben nach einer städtischen Bauaufsicht eröffnet gleichsam eine neue Phase der Stadtgestaltung, die sich zuerst aus einem ganz besonderen Typ von Senatsurkunden, nämlich den praxisbezogenen Schiedssprüchen der Magistri aedificiorum, die von 1227 an überliefert sind, ${ }^{55}$ erschließen läßt, um später in den Statuten normativ geregelt

balista vel lapide ubi sint fenestre vitree in ecclesia sancte Marie de Capitolio et in omnibus ecclesiis. Et qui contrafecerit solvat.c. sollidos prov. et hoc capitulum bandiatur."

53 Bartoloni, Codice diplomatico (wie Anm.1), Nr.98 und 99.

54 Vgl. u.a. Bartoloni, Codice diplomatico (wie Anm.1), Nr.76: „magistri positi et constituti a senatu et a populo Romano super questionibus murorum, domorum, viarum et platearum et divisionum intus Urbem et extra, et universorum hedificiorum".

Bartoloni, Codice diplomatico (wie Anm.1), Nr.73. Ausgewertet wurden diese Schieds- 
zu werden. Wegen des betrüblichen Verlustes der kommunalen Archive sind bis 1363 nur 21 dieser Sentenzen teils im Original der Empfängerausfertigung, teils als Abschrift, Insert oder Imbreviaturvermerk, teils nur als Empfehlung in einem vorbereitenden Rechtsgutachten erhalten; weitere sieben folgen bis $1400 .{ }^{56}$ In diesen Jahrzehnten muß außerdem ein eigenes Statut dieser Magistri promulgiert worden sein, das allerdings nur in der revidierten und ergänzten Fassung von 1410 erhalten ist. $^{57}$

Das Formular der Schiedssprüche entspricht im Aufbau und in der Wortwahl grob den Sentenzen des Senats, die in dieser Zeit im Einklang mit der zunehmenden Konsolidierung einer funktionierenden Verwaltung allmählich eine feste Form annahmen. Inhaltlich lassen diese Dokumente die Zuständigkeit des Senats für alle möglichen Angelegenheiten der baulichen Entwicklung ,intus urbem et extra" erkennen, ohne daß der räumliche Kompetenzbereich nach außen genau abgegrenzt wäre. Die Befugnisse der Magistri erstreckten sich wohl von Anfang an sowohl auf Baumaßnahmen an den Grundstücksgrenzen der Besitzungen von Institutionen und Bürgern innerhalb der Stadtmauern als auch auf Grenzstreitigkeiten um Ackerland außerhalb der Stadt..$^{58}$

Die Bemühungen um eine planmäßige Stadtgestaltung galten speziell der Festsetzung von Maßen für Vorbauten wie Loggien, Portiken und Außentreppen in den Stadtteilen. Das Kapitel von San Pietro konnte beispielsweise 1233 mittels eines Richterspruchs der Magistri in der Leostadt durchsetzen, daß die Vorbauten der Häuser an den Straßen und Plätzen um die Kirche und insbesondere in der Ruge Francigene, der Fortsetzung der via Francigena, die von der Porta S. Petri oder S.Peregrini ( $R$ auf der Karte) direkt zur Basilika führte, nicht mehr als sieben Palmi in den Straßenraum hineinragen durften..$^{59}$ Der römische Palmo oder Palmo des Senats war ein auf Rom und seinen näheren Einzugsbereich

sprüche von Cristina Carbonetti Vendittelli, Documentazione inedita riguardante i Magistri edificiorum Urbis e l'attività della loro curia nei secoli XIII e XIV, in: Archivio della Società romana di storia patria 113(1990), S.169-188 mit der Edition von Dokumenten; dies., La curia dei magistri edificiorum Urbis nei secoli XIII e XIV e la sua documentazione, in: Rome aux $\mathrm{XIII}^{\circ}$ et $\mathrm{XIV}^{\circ}$ siècles. Cinq études réunies par Étienne Hubert (Collection de l'École Française de Rome 170), Rom 1993, S.1-42.

56 Zusammengestellt bei Carbonetti Vendittelli, La curia dei magistri edificiorum Urbis (wie Anm. 55), S.33-38.

57 C. Scaccia Scarafoni, L'antico statuto dei „Magistri stratarum“ e altri documenti relativi a quella Magistratura, in: Archivio della Società romana di storia patria 50(1927), S.239-308.

58 Vgl. u.a. Bartoloni, Codice diplomatico (wie Anm.1), Nr.73 von 1227 und Nr.90 von 1238; vgl. Carbonetti Vendittelli, La curia dei magistri edifiiorum Urbis (wie Anm.55), S. 33 mit weiteren Editionen.

59 Bartoloni, Codice diplomatico (wie Anm.1), Nr.76 von 1233: „arbitramur et precipimus quatinus habitatores dicte civitatis qui habent proforula et porticalia ante domos eorum a frontibus ipsarum eorum domorum versus viam cogantur secare et removere quod plus est .vij. palmorum". 
beschränktes Längenmaß, bestehend aus zwölf Unzen. Die Vorschrift sollte wohl hauptsächlich verhindern, daß die Wege der zahlreich durch das Viertel strömenden Pilger vollends mit Schankstuben, Verkaufsbuden und Marktständen versperrt würden. Und 1279 erfolgte eine weitere Fallentscheidung zur kompromißlosen Freihaltung des Petersplatzes, in den kein Haus weiter hineinragen dürfe als der anliegende Portikus eines Gebäudes des Ospedale S. Spirito. ${ }^{60}$ Solche Versuche einer rechtlichen Steuerung betrafen also unmißverständlich den gemeinschaftlichen Raum, insbesondere Haupt- und Prachtstraßen sowie repräsentative Plätze, deren politische, wirtschaftliche und gemeinschaftsstiftende Funktionen allgemein bekannt waren, weil dort Herrschereinzüge, Festprozessionen, Märkte und Bürgerversammlungen mit größtmöglicher Öffentlichkeitswirkung stattfanden. Private Interessen mußten, zumindest den Urteilssprüchen der Baubehörde zufolge, dahinter zurücktreten.

Andere Sentenzen der Magistri galten der Rettung von Bauwerken vor dem Abbruch sowie der Sauberhaltung der öffentlichen Straßen von Abfällen und Abwässern, also einer wohlgeordneten und sauberen Stadt. Ein Rechtsgutachten empfahl beispielsweise 1255, einen römischen Bürger und seine Ehefrau von Amts wegen davon abzuhalten, Teile oder gar das gesamte Gebäude einer Mühle aus dem Besitz der Kirche S. Maria in Trastevere am rechten, transtiberischen Ufer des Tiber zu zerstören. ${ }^{61}$ Und einigen jüdischen Färbern neben der kleinen Kirche S. Maria Domnae Bertae, am Rande des Judenviertels unweit des Marcellustheaters und der Kirche S.Nicola in Carcere, wurde auf Antrag des zuständigen Pfarrers 1238 verboten, weiterhin ihre Tinkturen und Farbstoffe, genannt aqua tinte et tinta, vor ihrer Werkstatt auf die öffentliche Straße zu schütten, weil das stinkende Schmutzwasser stets direkt vor den Eingang des Gotteshaus fließen würde; die Handwerker erhielten nun die rechtskräftige Auflage, das Schmutzwasser über einen verdeckten Kanal bis zur cloaca maxima zu leiten. 62

Mit der Nutzungskontrolle von öffentlichem Boden richtete sich die Aufmerksamkeit der Behörde nicht nur auf die notwendigen Abwasserkanäle, sondern auch auf die zweckmäßige $\mathrm{Zu}$ - und Ableitung der Wasserversorgung. Im Falle der oberen Mühle des Dominikanerinnenkonvents S. Sisto entfaltete sich beispielsweise von 1260 bis 1263 ein jahrelanger nachbarlicher Streit um den Zugang zu einem Wasserlauf, der die Grenze zwischen einem privaten Garten

60 Vgl. Carbonetti Vendittelli, La curia dei magistri edificiorum Urbis (wie Anm.55), S.35, Nr.12.

61 Bartoloni, Codice diplomatico (wie Anm.1), Nr.131 von 1255: „damus consilium vobis iam dictis [domnis] magistris quatinus proybeatis Romanum Citadani predictum ut non diruat nec dirui faciat dictos staffines seu monumentum predicti molendini ipsius ecclesie".

62 Bartoloni, Codice diplomatico (wie Anm.1), Nr.94 von 1238: ,faciant dicti Ebrei in via sub terra aliquem cursum coopertum usque ad clavicam"; vgl. Hubert, Espace urbain (wie Anm.8), S.121. 
und einer öffentlichen Straße markierte. Die Nonnen wollten ihn ausheben und reinigen, um die Geschwindigkeit des Wassers zu beschleunigen und dadurch seine Kraft besser nutzen zu können. ${ }^{63}$ Durch den Ausbau und die Regulierung des Wasserarmes sollte also die wirtschaftliche Rentabilität der Mühlenanlage gesteigert werden. Die kommunale Baubehörde konnte eine solche Instandsetzung gegen den Widerstand der anderen Anlieger erlauben, weil der Bach die öffentliche Straße begrenzte und damit der Zuständigkeit des Senats unterstand. Auch Entscheidungen über die Wasserzufuhr, Zufahrtswege und Grenzziehungen der außerhalb der Stadt gelegenen Weinberge und Köhlereien unterstanden den Magistri, ${ }^{64}$ deren Kompetenz lange vor den kapitolinischen Wassermeistern des 14.Jahrhunderts das innerhalb der Stadtmauern gelegene Areal deutlich überschritt. Vor allem wenn der öffentliche Raum tangiert war, mußten selbst frisch gebaute Mauern wieder eingerissen und verändert werden. ${ }^{65}$ Die Bauverwaltung des Senats konnte allerdings nur private Vorhaben genehmigen, unterstützen oder verhindern; eigenständige kommunale Planungen für die räumliche Organisation der Stadt existierten noch kaum.

Obwohl also Statuten und allgemeine Bauvorschriften für diese Phase der kommunalen Entwicklung noch fehlen, zeigen uns die lückenhaft und zufällig überlieferten Senatsurkunden und Notariatsinstrumente des 13.Jahrhunderts eindringlich die Bemühungen um eine geregelte Bauplanung und damit die zunehmende Verantwortung der Kommune für das Aussehen der Stadt und das Wohl der Bewohner. Wenngleich sich daraus nicht unbedingt eine gesetzgeberische Systematik ableiten läßt, zeigen die Einzelfälle doch eindrucksvoll, wie die städtische Führung eine Durchsetzung der Normen zum Schutz des öffentlichen Raumes anstrebte.

Die Statuten von 1363 führten die in den Rechtsverfahren behandelten Themen fort. Sie verordneten etwa die genaue Straßenbreite für die vie vicinales, also die einfachen Wege in den Stadtteilen, deren Spannweite dem Längenmaß des Senats zufolge auf genau vier Palmi festgelegt wurde, ${ }^{66}$ so daß wohl gerade zwei Fußgänger aneinander vorbeigehen konnten. Eine solche Kontrolle öffentlicher Verbindungswege war nicht neu; auch über die angemessene Distanz zwischen Anliegern war bereits früher diskutiert worden. Bereits 1255 hatten die

63 Cristina Carbonetti Vendittelli, Le più antiche carte del convento di San Sisto in Roma (905-1300), Roma 1987 (Codice diplomatico di Roma e della regione romana 4), Nr.132, 142 und 144; vgl. Carbonetti Vendittelli, La curia dei magistri edificiorum Urbis (wie Anm.55), S.34.

64 Bartoloni, Codice diplomatico (wie Anm.1), Nr.129 von 1255: „eExtra portam Sancti Petri loco qui dicitur ad Almacia".

65 Vgl. u.a. Bartoloni, Codice diplomatico (wie Anm.1), Nr.73 von 1227; Carbonetti Vendittelli, La curia dei magistri edificiorum Urbis (wie Anm.55), S.33-34, Nr.1 und 10.

$66 \mathrm{Re}$, Statuti della città di Roma (wie Anm.6), S.161, \$2 zu Lib.2, cap. CXXXV: „Statuimus et ordinamus quod vie vicinales debeant esse ample per quatuor palmos ad palmum et mensuram Senatus." 
Magistri nach einer eingehenden Ortsbesichtigung außerhalb der Porta S.Petri ( $R$ auf der Karte) mittels einer Sentenz verfügt, welchen Abstand eine Köhlerei von den benachbarten Weinbergen zu halten habe und wie die öffentliche Straße dazwischen zu gestalten war. ${ }^{67}$ Häufig hatte sich gerade im eng bebauten abitato auch nachbarschaftlicher Streit um den Umgang mit gemeinsamen Mauern erhoben. Die Statuten schrieben vor, daß es jedem Anlieger einer solchen Grenzmauer erlaubt sein müßte, seine Dachbalken daran zu befestigen und weiteren Nutzen daraus zu ziehen, ohne allerdings das anliegende Haus zu zerstören. ${ }^{68}$

Kaum normiert war in Rom, im Gegensatz zu den anderen italienischen Städten auf kleinerem Areal, das Bauen auf eigenem Grund und Boden. Der Höhe der Gebäude waren, den Statuten zufolge, keine Grenzen gesetzt. ${ }^{69}$ Die im Auftrag der popolaren Regierung tätigen Gesetzgeber unterschieden im Statut über das unerlaubte Werfen von Steinen aus privaten Gebäuden nur zwei Haustypen, einerseits die turris oder domus maior, also Gebäude mit mehr als fünf Stockwerken ("quinque palariarum"), deren Konfiskation mit der Bezahlung von $50 \mathrm{Lb}$. abgewendet werden konnte, und andererseits die niedrigere domus bis zu fünf Stockwerken, die bereits für $25 \mathrm{Lb}$. auszulösen war. Sonderbedingungen galten für eine domus incastellata, also eine stark befestigte Anlage ohne Turm, und eine „domus comunis inter plures consortes", also einen gemeinsamen Hausbesitz im Konsortium. ${ }^{70}$ Die Unterscheidung zwischen Wohnturm („turris“) und Wohnhaus („,domus") war bereits älteren Ursprungs, zumindest behauptet dies ein anderes Statut über die Restitutionsbedingungen für enteig-

67 Vgl. Bartoloni, Codice diplomatico (wie Anm.1), Nr.129, S.206-209.

Re, Statuti della città di Roma (wie Anm.6), S.61, Lib.1, cap.XCII: „De parietibus comunibus. Si aliquis paries inter aliquos fuerit comunis quilibet eorum in ipso sit licitum trabes mictere et ex eo utilitatem habere sine destructione domus."

69 Re, Statuti della città di Roma (wie Anm.6), S.65, Lib.1, cap.CI: „De edificantibus in possessionibus suis. Quilibet in sua possessione et solo possit in altum edificare pro libito voluntatis statuto aliquo vel prohibitione in contrarium non obstante."

$70 \mathrm{Re}$, Statuti della città di Roma (wie Anm.6), S.114-115, Lib.2, cap.LXIII: „Item si de aliqua turri vel domo maiori quinque palariarum proiecti fuerint lapides in aliquo prelio bactalia vel rissa, conffischetur Camere Urbis dicta domus vel turris salvo quod si redimere voluerit domum vel turrim quod liceat illi cuius est domus vel turris reddimere pro .1. libris. Si vero fuerit lapidatum de domo quinque palariarum vel infra liceat reddimere pro .xxv. libris prov, excepto quod si lapidatum fuerit de mandato Curie vel ad defensam domini dicte domus vel turris et habitantis in ea. Et salvo si apparuerit aliquando domini Senatoris quod dicta domus incastellata et de ea fuisset lapidatum contra partem illius cuius est domus in rissa vel prelio suo vel alterius cuiuscunque domini ipso domino domus absente de contrata dicte domus tunc dominus non sit in dicta pena, set qui incastellaverit seu qui incastellari fecerit dictam domum vel lapidaverit vel lapidari fecerit de dicta domo puniatur in dicta pena. Set si proiecti vel lapidati fuerint lapides de domo comuni inter plures consortes in prelio vel rissa unius de consortibus vel aliquorum, ille pro parte cuius fuerit lapidatum teneatur redimere et solvere dictas penas, quod si non redimeret curia procedat ad confischationem partis sue tantum." Vgl. Hubert, Espace urbain (wie Anm. 8), S.175 und 193. 
nete oder zerstörte Baukomplexe, das sich ausdrücklich auf Gewohnheitsrechte („consuetudines“) aus Zeiten des Senators Matteo Rosso Orsini (1241-1242) beruft. Ziel war die pauschale Festlegung von Ersatzleistungen, die bei enteigneten oder zerstörten Kastellen, Wohntürmen, Burgen und Befestigungen („castra“, „turres“, „arces" und „munitiones") mit mehr als fünf Stockwerken deutlich höher ausfielen als bei einfachen Häusern. ${ }^{71}$ Die eingeforderten Strafsummen waren im Sinne der gesetzgeberischen Ausrichtung gegen die Ausschreitungen, Gewalttätigkeiten und Fehden der Oberschicht innerhalb der Stadt wiederum nach der Zugehörigkeit der Delinquenten zum Stand von Fußvolk, städtischem Rittertum bzw. cavallarotti sowie Magnaten gestaffelt.

Das konkrete Aussehen der Häuser ist aus den römischen Notariatsinstrumenten der Zeit allerdings leichter zu ermitteln. ${ }^{72}$ Die Statuten regeln nur umstrittene Details, um die sich regelmäßig Streitigkeiten rankten. Ein Sicherheitsproblem im eng bebauten abitato waren offensichtlich überdimensionale Wasserrinnen und Dachtraufen, deren Existenz in Häusern, sei es auf dem Dach, in der Wand oder an einem anderen höheren Platz, als gesetzwidrig galt und deren Installation deshalb jedermann unter strengsten Auflagen untersagt wurde. Auf diese Weise sollte verhindert werden, daß Wasserkaskaden das Eingangstor eines fremden Hauses blockierten oder in feindlicher Absicht herabgeschüttet wurden. ${ }^{73}$

Der Gesetzgeber forderte zudem die Ankündigung neuer Bauvorhaben, um den verbotenen $A b r i ß$ älterer Gebäude zu verhindern, gravierende Veränderungen im Stadtbild abzuwenden und anderweitige Kontrollen auszuüben. Allerdings waren die städtischen Leitungsgremien immer auf Kläger angewiesen, die ihre Ansprüche vor Gericht innerhalb genau gesetzter Fristen durchzusetzen hatten. ${ }^{74}$ Gesetzlich normiert wurden deshalb vor allem öffentliche Belange.

71 Re, Statuti della città di Roma (wie Anm.6), S.130-131, Lib.2, cap.LXXXI: „De auferentibus castra turres arces et domos et violentiis eorumdem. Item adherentes antique consuetudini sumpte ex privilegio domini Macthei rubei dudum senatoris, statuimus quod si quis quocumque tempore abstulerit alicui turrim castra vel arcem munitionem seu domum ultra v. palarias altam vel etiam dirruerit, Senator illico et sine mora et sine aliquo quocumque iudicio res predictas restitui et deliberari faciat in ea qualitate et quantitate in qua fuerit tempore maleficii perpetrati.“

72 Ausführlich bei Hubert, Espace urbain (wie Anm. 8), S.169-232.

$73 \mathrm{Re}$, Statuti della città di Roma (wie Anm. 6), S.181, Lib.2, cap. CLXXVIII: „De tenentibus canalem et stillicidia contra ius in domo. Nullus in tecto seu pariete nec etiam in aliquo alio loco habeat nec habere nec tenere debeat canalem stillicidium sive stillicidia aliquam vel aliqua per quam sive per quem aqua currat sive caddat ad hostium in hostio sive prope hostium, sive in introytum domus aliene et quicumque habet vel habent ad pensionem illius vel illorum in cuius vel quorum hostio domus cadere vel prope hostium teneatur et debeat elevare ad penam .x. librarum prov. ,cuius pene medietas sit accusantis et reliqua sit Camere et possit quilibet accusare et nichilominus debeat dictum canale sive stillicidium elevare."

$74 \mathrm{Re}$, Statuti della città di Roma (wie Anm. 6), S.64f., Lib.1, cap. C. 
Beispielsweise durften die Häuser von Mördern nicht zerstört werden, sondern sie sollten jeweils zur Hälfte der Camera Urbis und den Hinterbliebenen des Getöteten zufallen. ${ }^{75}$ Weitere Bestimmungen regelten die Annulierung von Immobilienverkäufen im Fall von Unrecht, Gewalt und Belästigung, ${ }^{76}$ die Rückerstattung erschlichener Erträge aus Immobilien ${ }^{77}$ oder die Pflicht, den Immobilienbesitz römischer Bürger im districtus Urbis zu verteidigen. ${ }^{78}$

Großes Gewicht legten die Statuten auf die Abfallbeseitigung, also eine saubere Stadt. Anscheinend waren schon damals die Außenzonen um die Stadttore besonders beliebt, um unerwünschten Unrat abzulagern. Eine entsprechende Vorschrift bezog sich deshalb auf das Gelände bei der Porta Septimiana, dem nördlichsten der drei Stadttore von Trastevere $(N)$; gerade der zu jeder Tageszeit stark frequentierte Weg nach St.Peter, die sogenannte via sancta, sollte unbedingt von Verschmutzungen frei bleiben. ${ }^{79}$ Ähnliches galt für die traditionelle Wettkampfzone in agone, also die heutige Piazza Navona, auf der am Donnerstag vor Beginn der Fastenzeit das große Fest der römischen Kommune begann. Diese Karnevalsspiele wurden durch das bürgerliche Regime, das die Statuten aufzeichnen ließ, besonders gefördert. Für den campus agonis drohten deshalb bei bewußter Verschmutzung sogar beschleunigte Anklageverfahren. ${ }^{80}$ Auch der Fluß sowie alle öffentlichen Straßen und Plätze hatten von Jauche („mortulata“), Gerberresten („consatura coraminis") und anderem Müll frei zu bleiben, weil dieser Unrat nur die Luft verseuchen und stören würde. Selbst für private Hausanlagen mußte die Ablagerung von Mist („stabium") und anderem Abfall verboten werden. Und den Metzgern wurde untersagt, Tierblut, Fleischstücke

75 Re, Statuti della città di Roma (wie Anm. 6), S.94, Lib.2, cap.XVI: „Pro honore Urbis statuimus quod domus homicide non diruantur sed ipse domus pro medietate adiudicentur Camere Urbis et pro alia medietate heredibus occisy."

$76 \mathrm{Re}$, Statuti della città di Roma (wie Anm. 6), S.131, Lib.2, cap.LXXXI, \$1.

$77 \mathrm{Re}$, Statuti della città di Roma (wie Anm. 6), S.132, Lib.2, cap.LXXXI, §2.

$78 \mathrm{Re}$, Statuti della città di Roma (wie Anm. 6), S.132, Lib.2, cap.LXXXI, \$3.

79 Re, Statuti della città di Roma (wie Anm. 6), S. 187, Lib. 2, cap. CXC: „De immundicia non proicienda ad portam septingianam nec in agone. Nullus vel nulla proici faciat aliquam immundiciam seu aliquam turpitudinem vel susuram ad portam septingianam seu retro muros ipsius porte. Cum per ipsam viam omni tempore romani femmine et masculi ad sanctum petrum vaddunt, et ipsa via semper appelletur via sancta, qui contrafecerit solvat .x. sollidos prov. Camere Urbis, ponantur aliqui qui denuntient facientes contra predicta."

$80 \mathrm{Re}$, Statuti della citta di Roma (wie Anm. 6), S.189, Lib.2, cap. CXCV: „De immundicia non proicienda in agone. De cetero nullus audeat, proicere in campo agonis finum vel aliquam putredinem, et qui contrafecerit teneatur solvere pro qualibet vice $x$. sollidos prov. et fiant accusationes celati super hiis, qui iurent predicta fideliter facere, habeant quam medietatem pene et alia medietas applicetur Camere Urbis, et predicta bandiantur." $\mathrm{Zu}$ den Festivitäten vgl. Andrea Sommerlechner, Die ludi agonis et testatie - das Fest der Kommune Rom im Mittelalter, in: Römische Historische Mitteilungen 41 (1999), S.339-370. 
oder ganze Tierkörper auf Plätze und öffentliche Wege zu werfen ${ }^{81}$ Nicht zuletzt war stehendes Wasser in der Stadt zu umgehen. Das durch die Porta Septimiana ( $\mathrm{N}$ auf der Karte) einfließende Regenwasser überschwemmte zum Beipiel immer wieder die Straßen in Trastevere, zumindest bis zur nahe beim Tor an der Lungara gelegenen Kirche S.Giacomo in Settimiano, Sitz der benediktinischen Silvestrinerkongregation. Um vor allem Seuchen zu verhindern, erfolgte die Anordnung, die Köhlerei vor den Mauern dieses Stadttores vollständig zu schließen und das angesammelte Wasser in den Tiber abzuleiten. ${ }^{82}$

Alle diese statutarischen Vorschriften könnte man vielleicht als Überlebensstrategie der kommunalen Stadtplanung bezeichnen, deren Aufgaben in den Schiedssprüchen der Bauaufsichtsbehörde vorgezeichnet waren. Denken wir nur an den Konflikt zwischen dem Priester der Kirche S. Maria Domnae Bertae und den jüdischen Färbern, die ihre stinkenden Tinkturen auf die Straße leerten, ehe sie zur Kanalisierung des Abwassers verurteilt wurden. ${ }^{83}$ Die Bauaufsicht versuchte bestenfalls, mit einem breitem Spektrum von Regelungen die schlimmsten Mißstände im öffentlichen Bereich, bezeichnet als communis und publicus, zu verhindern und Streitigkeiten zu schlichten, ohne allerdings eigenständige Baumaßnahmen zu etablieren. Die Vorkehrungen beschränkten sich auf ein gestalterisches Minimum, nämlich die Mindestbreite von Durchgangsstraßen zu normieren, neue private Bauvorhaben gesetzlich $\mathrm{zu}$ initiieren oder $\mathrm{zu}$ überwachen sowie den willkürlichen Abbruch von Häusern in bestimmten Fällen zu verhindern. Die maßgeblichen Kriterien der rechtlichen Steuerung waren anfangs Sauberkeit und Ordnung in der Stadt, welche die Statuten dann um den für das

81 Re, Statuti della città di Roma (wie Anm.6), S.189, Lib.2, cap. CXCIV: „De proicientibus immundicias in viis publicis. Nemo proiciat mortulatam vel consaturam coraminis seu aliam immundiciam seu proici faciat in aliqua platea seu via publica Urbis nisi in flumine tantum, cum aerem inficiat et conturbet et qui contrafecerit puniatur in $\mathrm{xx}$. solidos prov. Et nulla persona proiciat stabium vel aliam immundiciam in solo seu casalino alterius, et qui contrafecerit solvat qualibet vice .x. solidos prov. et hoc capitulum bandiatur, de qua pena medietas sit Camere et alia medietas sit accusantis. Et nullus macellarius vel alia persona proiciat sanguinem vel viscera animalium vel ipsa animalia mortua vel aliam turpitudinem, in aliqua platea vel via publica, sub pena .xl. sollidorum prov. nisi in flumen ut supra dictum est proiciat, quo casu ad penam non teneatur.“

Re, Statuti della città di Roma (wie Anm. 6), S. 188, Lib. 2, cap. CXCIII: „De remundando carbonarium porte septingiane. Cum aqua pluvina per portam septingianam decurrens repleat vias usque ad ecclesiam Sancti Iacobi, statuimus quod remundetur carbonarium quod est iuxta muros dicte porte totaliter et ut ex inde aqua congregata congreganda decurrat ad tyberim, et semper teneatur in eodem statu ne repleatur." Die Kirche ist erstmals erwähnt in dem zwischen 1313 und 1339 entstandenen Turiner Katalog, der dem Umfeld der Fraternitas Romana, der Organisation der römischen Weltgeistlichen, entstammen dürfte, deren Einteilung der stadtrömischen Kirchen in drei Gruppen er übernahm; vgl. Roberto Valentini und Giuseppe Zucchetti (Hg.), Codice topografico della città di Roma, Bd. 3, Roma 1946, S. 291-318, hier S. 317; Christian Huelsen, Le chiese di Roma nel Medio Evo, cataloghi ed appunti, Florenz1927, ND New York/Hildesheim 1975, S. 268. Bartoloni, Codice diplomatico (wie Anm.1), Nr.94 von 1238, S.155. 
bürgerliche Regime lebenswichtigen Aspekt der Sicherheit ergänzten. Ganz im Gegensatz zu anderen italienischen Stadtregierungen versuchten die popolaren Gesetzgeber Roms nicht, weitere verbindliche Instruktionen zu erteilen.

\section{Kommunales Bauen mit symbolhafter Bedeutung für die Gemeinschaft}

Angedeutet seien zuletzt noch kurz die wenigen eigenen, bereits oft erforschten und nur ungenügend bekannten kommunalen Bauvorhaben, soweit sie aus den Rechtsquellen hervorgehen. Mit der Erneuerung des römischen Senats 1143/1144 entstand auch das Bedürfnis nach einer lokalen Verortung der kommunalen Macht, also der Wunsch nach Räumlichkeiten für Beratungen, Gerichtsverhandlungen und Volksversammlungen. Wie in anderen Kommunen wurde auch in Rom im ersten Reflex auf Bestehendes zurückgegriffen: Die Kirche S.Martina am Forum wurde als Ort für Versammlungen genutzt, die im Verfall begriffenen Gebäude der Corsi-Sippe über dem antiken Tabularium auf dem Kapitol wurden zum Senatorenpalast umfunktioniert. ${ }^{84}$

Da die Bauten selbst zerstört sind, geben uns insbesondere für die Frühphase wiederum einige Senatsurkunden und andere Rechtstexte entscheidende Anhaltspunkte. Einige Jahre nach der Kommunegründung wurde 1151 der Friedens- und Handelsvertrag mit Pisa auf dem Kapitol ausgestellt, und zwar im neuen Konsistorium des Palastes (,in consistorio novo palatii“). ${ }^{85}$ Dies bedeutet, daß der Komplex von Seiten der kommunalen Amtsträger als neu betrachtet und gleichzeitig für repräsentative Zwecke im Umgang mit anderen Kommunen genutzt wurde. Daes bestätigt auch ein späterer Schiedsspruch, in dem die Senatoren 1160 beiläufig das Kapitol als regelmäßigen Versammlungsort des jährlich neu gewählten großen Senates erwähnen. ${ }^{86}$ Es kann sich also wohl kaum nur um notdürftige Ausbesserungen der Ruinen gehandelt haben, sondern es muß auch nach den Informationen des zeitgenössischen Theologen Gerhoh von

84 Zur Baugeschichte vgl. Serena Romano, La facciata medievale del Palazzo Senatorio: i documenti, i dati, e nuove ipotesi di lavoro, in: La facciata del Palazzo Senatorio in Campidoglio. Momenti di storia urbana in Roma, hg. von Eugenio La Rocca, Ospedaletto 1994, S.39-62, hier S.41; Krautheimer, Rom. Schicksal einer Stadt (wie Anm. 8), S.229ff. und 312f.; Carlo Pietrangeli, Il Palazzo Senatorio nel Medioevo, in: Capitolium 35 (1960), S.3-19; ders., I palazzi capitolini nel Medioevo, in: Capitolium 39(1964), S.191-194; Gramaccini, Mirabilia. Das Nachleben antiker Statuen (wie Anm.40), S.169ff. zur Platzgestaltung.

85 Bartoloni, Codice diplomatico (wie Anm.1), Nr.11 S.13 im Vertrag mit Pisa vom 12. März 1151.

86 Bartoloni, Codice diplomatico (wie Anm.1), Nr.17 S.23 in einer Senatsurkunde vom 23.Januar 1160: , ,in novo consistorio senatus annuatim in Capitolio constituti“. 
Reichersberg zu urteilen ${ }^{87}$ - ein geplanter Ausbau auf Kosten der neu gegründeten Gemeinschaft stattgefunden haben. Dadurch wurde der Palast auf dem im Osten des abitato gelegenen Hügel zu einem Zentrum städtischen Lebens und zum Sinnbild von wieder errungener Autonomie und Freiheit.

Welche Baumeister für die Kommune arbeiteten, läßt sich mangels entsprechender Indizien nicht mehr feststellen. Immerhin verweist eine Inschrift an dem S. Gregorio Nazianzeno geweihten Tragaltar in der Titelkirche S.Maria in Porticu, später S.Maria in Campitelli, auf den Senat als einen potentiellen Auftraggeber. Die Signatur „Senatus G(re)G(orius) aurifex“ deutet auf einen Künstler, der von außen kommend für die römische Kommune tätig wurde, aber wohl kaum fest in deren Diensten stand. ${ }^{88}$ Als Abnehmer von Kunstwerken und Bauten hinterließ der Senat also ganz im Gegensatz zum Papsttum des 12.Jahrhundert nur wenige Spuren.

Eine eigenständige kommunale Bautätigkeit, die über Restaurierung und Überwachung des vorhandenen Baubestands hinausging, wird für Rom wie für die meisten anderen Städte erst in einer späteren Phase der Kommuneentwicklung faßbar, nämlich erst als sich mit dem Wechsel zu neuen, auf wenige Machthaber beschränkten Herrschaftsformen das Bedürfnis nach Selbstdarstellung und Herrschaftslegitimation verstärkte. Während in den Jahren 1191 bis 1204 ein mehrmaliger Umschwung zwischen einem oligarchisch geprägten 56-köpfigen Senatskollegium und einigen allein oder zu zweit regierenden, antipäpstlichen und teilweise vom Volk ernannten Senatoren stattfand, setzten sich dann in blutigen Unruhen und Parteikämpfen letztlich einzelne, eher papsttreue Senatoren durch, deren Herkunft anfangs nicht einmal immer zu ermitteln ist, ehe in den dreißiger Jahren verstärkt die führenden Baronalfamilien aus der kaiserlichen Partei in den Senat drängten. ${ }^{89}$ Gemäß dem Trend der Stadtmagnaten zum Residieren entstanden damals in den meisten Städten Italiens monumentale

87 Gerhoh von Reichersberg, Commentarium in psalmum XUIV, in: MGH, Libelli de lite imperatorum et pontificum saeculis XI. et XII. conscripti 3, hg. von Ernst Dümmler/ Ernst Sackur u.a., Hannover 1897, S.462: „ut Roma apparet in ede Capitolina olim diruta et nunc reedificata“; vgl. Jürgen. Paul, Die mittelalterlichen Communalpaläste in Italien, Diss. Freiburg 1963, S.255; Romano, La facciata medievale (wie Anm. 84), S. 40.

88 Arduino Colasanti, Reliquiari medioevali in chiese romane, in: Dedalo 13(1933), S.290 und Abb. S.294; Paolo Brezzi, Roma e l'impero medioevale (774-1252) (Storia di Roma, Bd.10), Bologna 1947, S. 290 erwähnt ihn für die Zeit von Paschalis II.; Moscati, Alle origini del Comune Romano (wie Anm.3), S.70-71; Antonietta Valente, Intorno ad un orafo del secoloXII, in: Bolletino d'Arte 31(1937/38), S.261-267, bes. 264. Zu einem Gregor unter den „marmorarii Romani“ vgl. Peter Cornelius Claussen, Magistri doctissimi romani. Die römischen Marmorkünstler des Mittelalters, Stuttgart 1987 (Corpus cosmatorum 1; Forschungen zur Kunstgeschichte und christlichen Archäologie 14), S.236.

89 Zur vielgestaltigen Entwicklung des Verhältnisses zwischen Adelssenat und kommunaler Führung bis $1268 \mathrm{vgl}$. Thumser, Rom und der römische Adel (wie Anm.3), S.239343. 
Kommunalpaläste. Auch in Rom dürfte spätestens in der Mitte des 13. Jahrhunderts ein zusätzlicher Palast auf dem Kapitol errichtet worden sein, als nach einer Erhebung des mittelständischen Popolo im Sommer 1252 auswärtige Senatoren die Regierungsgeschäfte bis 1258 übernahmen und insbesondere der aus Bologna berufene Capitano del Popolo Brancaleone degli Andalò erbarmungslos gegen die Magnaten vorging. Unter seinem Regiment unterschieden die Protokollnotizen zu einem Friedensvertrag zwischen Rom und Tivoli aus dem Jahr 1257 erstmals ein palatium vetus, den Raum für die Versammlung eines allgemeinen Rates, vom palatium novum, dem Gebäude für die Zusammenkunft des Ältestenrates..$^{90}$ Mit dem Übergang der Regierungsgeschäfte auf ein kleineres Gremium mußte sich notgedrungen auch die innere Gestaltung der äußerlich stark befestigten Gebäude verändern.

Mit der organisatorischen Ausrichtung auf einen einzigen Senator, der sein Handeln öffentlich legitimieren mußte, konnte die bauliche Gestaltung zu üppigeren Formen gedeihen; die Baumaßnahmen wurden zu einem Mittel der Selbstdarstellung. Deutlich zu erkennen ist diese Tendenz bei der Ausstattung des Kapitolsplatzes, die von kunsthistorischer Seite bereits ausführlich analysiert wurde..$^{91}$ Leider ist nicht immer bekannt, wann genau einzelne Modifikationen erfolgten, so daß die politischen Implikationen oft nur zu vermuten sind. Besonders strittig ist etwa der Zeitpunkt, zu dem der auf vier Löwenstützen ruhende kapitolinische Obelisk zweifellos unter größten Anstrengungen aufgestellt wurde; der stilistische Befund deutet auf die Jahrzehnte vor 1200, möglicherweise sogar die kommunale Entwicklungsphase zwischen 1150 und 1160; jedenfalls spätestens zur Zeit Brancaleones dürfte der ägyptische Obelisk dem Ensemble auf dem Kapitol ein würdevolleres Aussehen verliehen haben.92

Die Rechtsquellen spiegeln solche Zusammenhänge ohnehin nur im Ausnahmefall. Der Löwe war bekanntlich das Wahrzeichen der römischen Kommune; nicht zuletzt zierte ein lebendiges Raubtier den Graben um den Senatorenpalast. Die Statuten von 1363 erwähnen ein marmornes Löwendenkmal, das auf den 1348 erweiterten Treppen des Kapitols als Pranger diente. Der Rechtsbrecher wurde rittlings auf die Löwenstatue gesetzt, und zwar mit einer Mitra auf dem Kopf, auf der seine Schandtat beschrieben wurde, und mußte mit einem honigverschmierten Gesicht, in dieser mißlichen Haltung bis zum Ende des Markttages verharren. ${ }^{93}$ Solche Bekanntmachungen suggerieren, daß gerade eine

90 Bartoloni, Codice diplomatico (wie Anm. 1), Nr.136, bes. S.217-219.

91 Zusammenfassend Romano, La facciata medievale (wie Anm. 84); Gramaccini, Mirabilia. Das Nachleben antiker Statuen (wie Anm. 40), S.151-185.

92 Vgl. Romano, La facciata medievale (wie Anm.84), S.42; Gramaccini, Mirabilia. Das Nachleben antiker Statuen (wie Anm.40), S.170-175, beide erörtern auch das Problem der unterschiedlichen Datierungen.

93 Re, Statuti della città di Roma (wie Anm. 6), S.151, Lib.2, cap. CXX: „et si contrafecerit debeat poni eques in leone marmoris existente in scalis capitolii cum quadam mitra in capite in qua sit scriptus, inobediens mandati transgressor et faciem habeat untam de 
unter großem Legitimationsdruck stehende popolare Regierung gerne entsprechende Repräsentationsformen in Architektur und Plastik benutzte, um das Bedürfnis nach der lokalen Verortung und Darstellung kommunaler Herrschaft zu befriedigen. Der Bau von Räumlichkeiten und die Aufstellung öffentlich sichtbarer Hoheitszeichen waren dafür geeignete Mittel.

\section{Zusammenfassung}

Am Beispiel der Stadt Rom und des 1144 eingesetzten römischen Senats war der Zusammenhang zwischen normativen Regelungen zur Stadtgestaltung, den Formen der öffentlichen Bekanntmachung und der kommunalen Entwicklung bis zur ersten überlieferten Statutenkodifikation von 1363 zu veranschaulichen. Abschließend können die spezifisch römischen Bedingungen nochmals in drei Komplexen zusammengefaßt und verdeutlicht werden, nämlich in Hinblick auf die Erfassung des städtischen Raumes, die inhaltliche Zielsetzung der rechtlichen Regelungen und die Durchsetzung der Steuerungsversuche:

Erstens verfügte Rom im Gegensatz zu anderen Städten über ein enormes Gelände innerhalb der Stadtmauern, das nur rudimentär organisiert werden konnte und mußte. Die normativen Vorgaben des Senats betrafen fast ausschließlich die Gestaltung und Überwachung des öffentlichen Raumes, bezeichnet mit publicus oder comunis, so daß das Bauen auf eigenem Grund auch im 14. Jahrhundert noch kaum Einschränkungen unterworfen war. Die Maßnahmen galten vorwiegend neuralgischen Zonen wie Pilgerzentren, Hauptstraßen und Festplätzen.

Zweitens zielte die rechtliche Steuerung anfangs vorrangig auf einen wohl geordneten städtischen Raum und dessen Infrastruktur; Brücken und Wasserleitungen waren zu renovieren, die Stadtmauern wieder aufzubauen sowie Straßen und Wasserläufe zu regulieren. Weitere Bestimmungen und Rechtsentscheide versuchten dann, die Sauberkeit von Straßen und Plätzen zu verbessern. Erst die popolare Statutenkompilation von 1363, die zweifellos auf Vorläufer zurückgeht und eindeutig gegen die Willkürherrschaft der Magnaten gerichtet war, setzte sich intensiv mit dem Problem der innerstädtischen Sicherheit auseinander. Auch wenn das Bild der Quellen äußerst fragmentarisch ist, verfestigte sich der Eindruck, daß einige wenige Aufgaben des Gemeinwohls durchgehend im Zentrum der rechtlichen Vorschriften standen, während ästhetische Gesichtspunkte nur selten - etwa beim Antikenschutz - eine Rolle spielten.

Drittens erschwerte die anhaltende Konkurrenz zwischen päpstlicher und kommunaler Gerichtsbarkeit die Durchsetzung von Senatserlassen ebenso wie

melle et debeat manere ibi eques quo usque fuerit et duraverit mercatum." Vgl. Gramaccini, Mirabilia. Das Nachleben antiker Statuen (wie Anm.40), S.176-179. 
die Sanktionierung von Übertretungen. Die unterschiedlichen, sich abwechselnden kommunalen Führungsgruppen übernahmen die Regelungskompetenzen im Rahmen einer schrittweisen Institutionalisierung, die durch innerstädtische Kämpfe und radikale Umbrüche immer wieder gestört, aber nie ganz unterbrochen wurde. Da die Statutenkompilation offenkundig auf einer gewohnheitsrechtlichen Basis aufbaute, ist nicht immer klar, ob die Bestimmungen zum Zeitpunkt der Kodifikation überhaupt noch praktische Relevanz besaßen.

Unter Berücksichtigung dieser drei Prämissen lassen die überlieferten Urkunden, Sentenzen und Statuten vier Schwerpunkte einer baulichen Normierung und deren Propagierung erkennen: Erstens war die bald nach der Kommunegründung einsetzende Restaurierung von Stadtbefestigung, Zufahrtswegen, Brücken und Wasserleitungen zwangsläufiger Ausdruck der neu erworbenen kommunalen Autonomie; in diesem Zusammenhang waren Inschriften und Urkundenformeln wichtige Mittel der öffentlichen Propaganda. Zweitens gewann der Schutz antiker Monumente eine darüber hinausgehende Funktion; er war Ausdruck eines Bewußtseins von der antiken Schönheit der Stadt, verbunden mit einem innerstädtischen Machtanspruch, der in der konkurrierenden Gerichtsbarkeit einen wichtigen Antrieb erhielt. Drittens zeigen die Schiedssprüche der Magistri aedificiorum, die erstmals das mit dem Ausbau des kommunalen Ämterapparats einsetzende Streben nach einer planmäßigeren Bauaufsicht und Überwachung des Baubestands dokumentieren, wie der kommunale Zuständigkeitsbereich erweitert und zahlreiche Regelungen in Auseinandersetzung mit der Praxis geschaffen wurden. Viertens versuchten die Senatoren, angemessene Räumlichkeiten für Beratungen, Gerichtsverhandlungen und Volksversammlungen zu etablieren und dadurch das Bedürfnis nach einer Darstellung und Verortung ihrer Herrschaft zu befriedigen. In allen vier Bereichen liefern normative Quellen sichere Indizien dafür, wie sich das Bewußtsein vom städtischen Raum und seiner Gestaltung mit der kommunalen Entwicklung von der Mitte des 12. bis zur Mitte des 14. Jahrhunderts veränderte. 